Portland State University

PDXScholar

Summer 9-7-2017

\title{
Melting in the Mantle Wedge: Quantifying the Effects of Crustal Morphology and Viscous Decoupling on Melt Production with Application to the Cascadia Subduction Zone
}

Jiaming Yang

Portland State University

Follow this and additional works at: https://pdxscholar.library.pdx.edu/open_access_etds

Part of the Geology Commons, and the Tectonics and Structure Commons Let us know how access to this document benefits you.

\section{Recommended Citation}

Yang, Jiaming, "Melting in the Mantle Wedge: Quantifying the Effects of Crustal Morphology and Viscous Decoupling on Melt Production with Application to the Cascadia Subduction Zone" (2017). Dissertations and Theses. Paper 3880.

https://doi.org/10.15760/etd.5768

This Thesis is brought to you for free and open access. It has been accepted for inclusion in Dissertations and Theses by an authorized administrator of PDXScholar. Please contact us if we can make this document more accessible: pdxscholar@pdx.edu. 


\title{
Melting in the Mantle Wedge:
}

Quantifying the Effects of Crustal Morphology and Viscous Decoupling on Melt Production with Application to the Cascadia Subduction Zone

\author{
by \\ Jiaming Yang
}

A thesis submitted in partial fulfillment of the requirements for the degree of

\author{
Master of Science \\ in \\ Geology
}

Thesis Committee:

Maxwell Rudolph, Chair

John Bershaw

Leif Karlstrom

Portland State University 2017 


\begin{abstract}
Arc magmatism is sustained by the complex interactions between the subducting slab, the overriding plate, and the mantle wedge. Partial melting of mantle peridotite is achieved by fluid-induced flux melting and decompression melting due to upward flow. The distribution of melting is sensitive to temperature, the pattern of flow, and the pressure in the mantle wedge. The arc front is the surface manifestation of partial melting in the mantle wedge and is characterized by a narrow chain of active volcanoes that migrate in time. The conventional interpretation is that changes in slab dip angle lead to changes in the arc front position relative to the trench. We explore an alternative hypothesis: evolution of the overlying plate, specifically thickening of the arc root, causes arc front migration. We investigate the effects of varying crustal morphology and viscous decoupling of the shallow slab-mantle interface on melt production using $2 \mathrm{D}$ numerical models involving a stationary overriding plate, a subducting plate with prescribed motion, and a dynamic mantle wedge. Melt production is quantified using a hydrous melting parameterization. We conclude: 1) Localized lithospheric thickening shifts the locus of melt production trenchward while thinning shifts melting landward. 2) Inclined LAB topography modulates the asthenospheric flow field, producing a narrow,
\end{abstract}


well-defined arc front. 3) Thickening of the overriding plate exerts increased torque on the slab, favoring shallowing of the dip angle. 4) Viscous decoupling produces a cold, stagnant forearc mantle but promotes arc front melting due to reduction in the radius of corner flow, leading to higher temperatures at the coupling/decoupling transition. 


\section{TABLE OF CONTENTS}

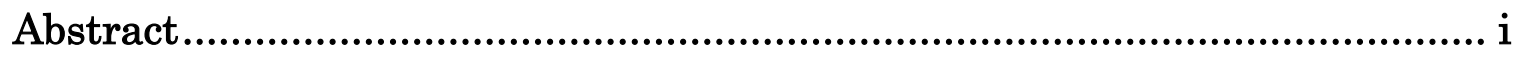

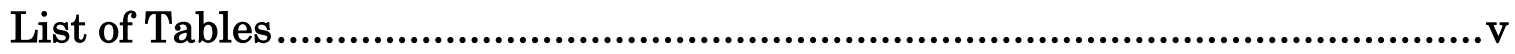

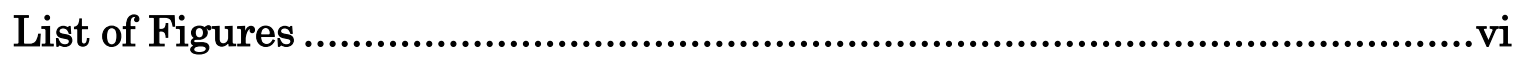

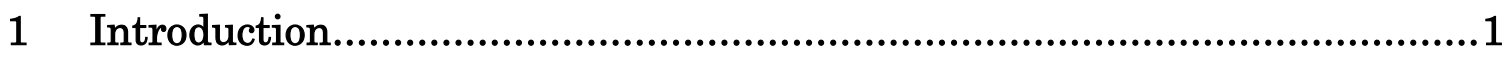

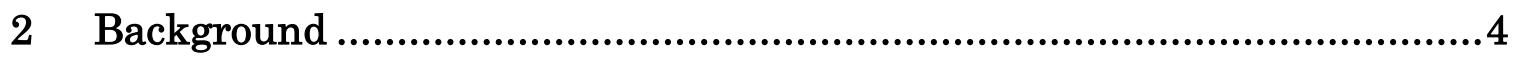

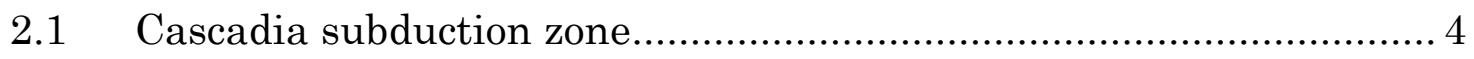

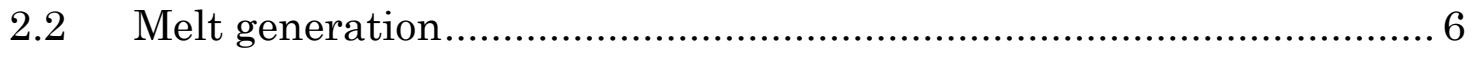

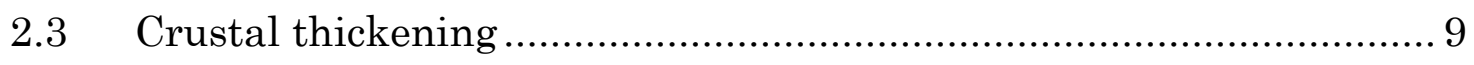

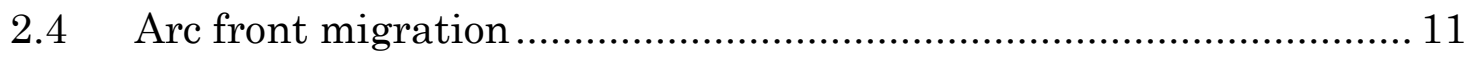

2.5 Viscous decoupling of the slab-mantle interface …......................... 15

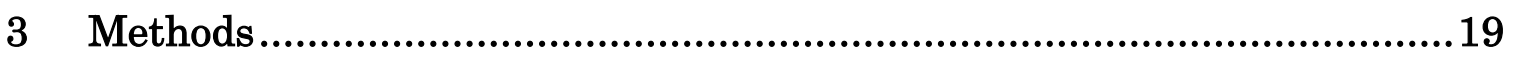

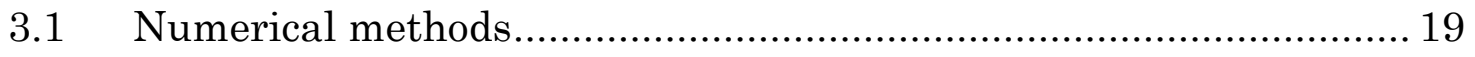

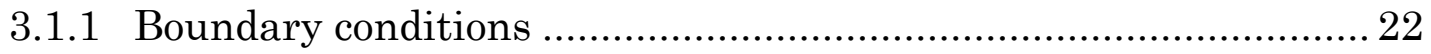

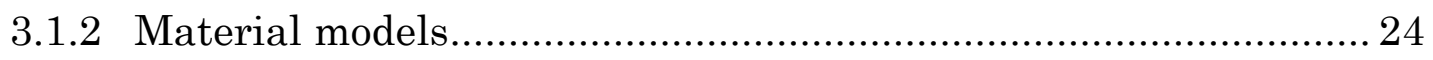

3.1.3 Summary of calculations and varying parameters ....................... 27

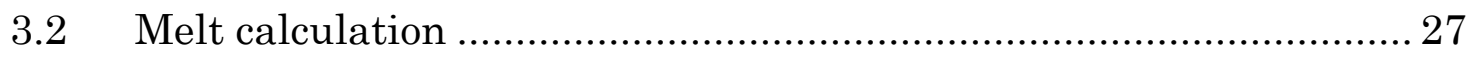

3.3 Model benchmark and resolution tests............................................ 30

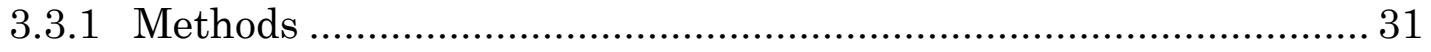




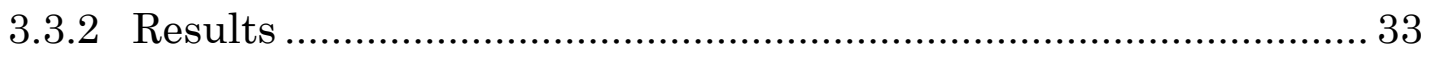

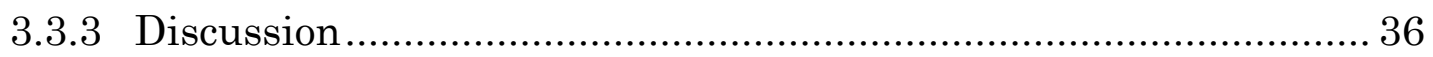

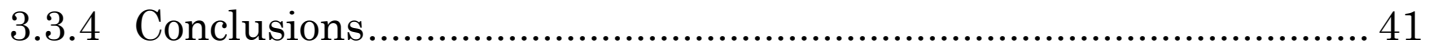

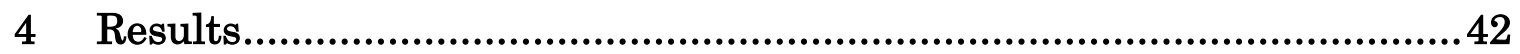

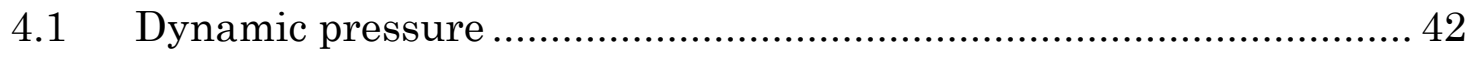

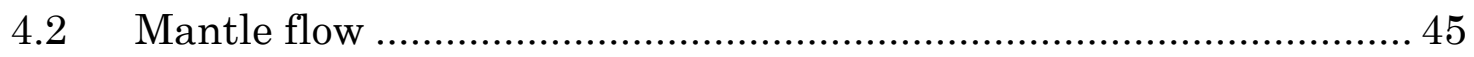

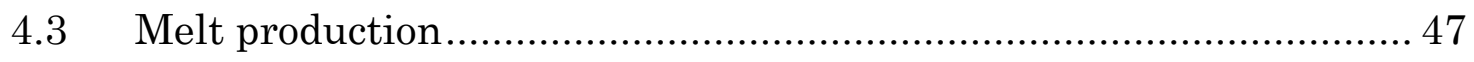

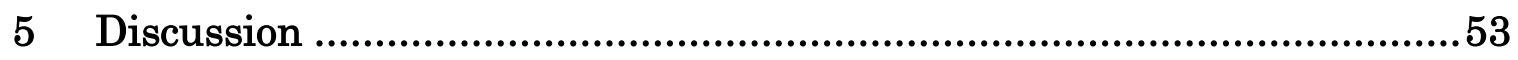

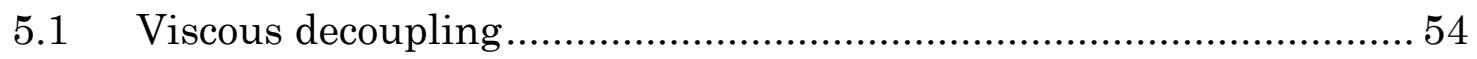

5.1.1 Controls on maximum depth of decoupling................................. 57

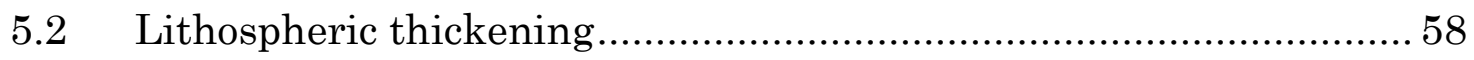

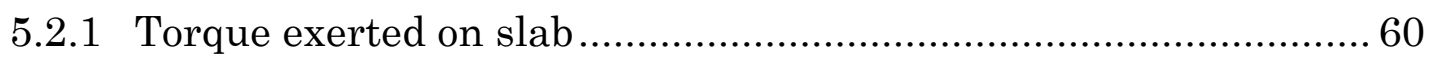

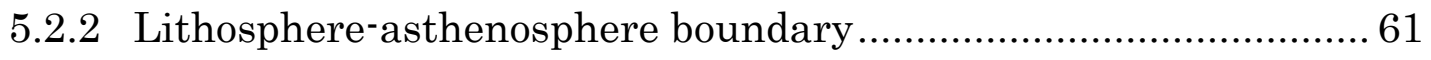

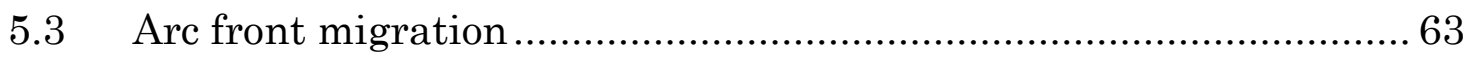

5.3.1 Landward migration and lithospheric thinning ........................... 66

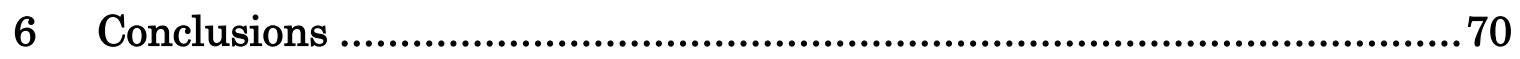

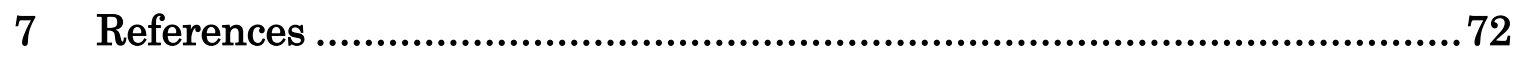




\section{LIST OF TABLES}

Table 1. Parameters and values used during modeling. ................................26

Table 2. Simulation configurations and free parameters used for subduction

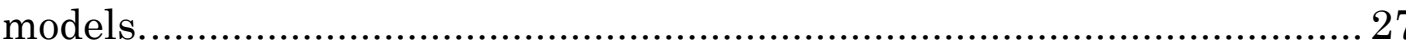

Table 3. Different grid resolution and Nusselt number solutions for thermal convection case 1a (Blankenbach et al. 1989). Percent Error was calculated using benchmark as the expected value. Standard deviation was given because the Nusselt number was calculated as a timeaveraged value in steady-state

Table 4. ANOVA results for the 3 fitted models shown in Figure 13............ 35

Table 5. Total melt production results for the various simulations. ..............52 


\section{LIST OF FIGURES}

Figure 1. Tectonic setting and GPS velocity vectors of Cascadia subduction zone (Wells et al., 2000)

Figure 2. Depth to slab contour map of the Cascadia subduction zone (Hayes

elt al., 2012) 6

Figure 3. Subduction zone modeling results of temperature, streamlines and decompression melting rate (contours). Upper panel shows the predicted distribution of volcanism(VF) as well as melt production rate along arc length (Conder et al., 2002).

Figure 4. (a) Peridotite solidus for different bulk water contents as a function of temperature and pressure. (b) Isobaric melting curves (1 GPa) showing the effects of temperature on melt fraction (modified from Katz et al., 2003)

Figure 5. Crustal thickness map of the central Cascadia subduction zone with with major Cascade volcanoes in black triangles. Data taken from Shen and Ritzwoller (2016), based on joint inversion of surface wave dispersion from ambient noise and earthquakes, Rayleigh wave $\mathrm{H} / \mathrm{V}$ ratio, and receiver functions. The subduction trench is shown as bold black line, based on the model of Bird (2003).

Figure 6. Map showing the locations of dated Western Cascade deposits along the west coast. From John et al. (2012). 
Figure 7. Global compilation of continental and oceanic arc data. (A) Ages of igneous rocks and relative distances to the trench. (B) Initial ${ }^{87} \mathrm{Sr} /{ }^{86} \mathrm{Sr}$ isotopic ratio and $(\mathrm{C})$ ratio of trace elements $\mathrm{La} / \mathrm{Yb}$. (modified from Karlstrom et al., 2014) 15

Figure 8. Thermal model of the Cascadia subduction zone showing the serpentinized forearc at the cold corner of the mantle wedge (Hansen et al., 2016). 17

Figure 9. (a) Idealized cross-section of an ocean-continent warm-slab subduction zone analogous to Cascadia, illustrating slab-mantle interactions and processes that occur in the mantle wedge. Green circle represents region of non-volcanic episodic tremor and slip. (b) Surface heat flow curve incorporating wedge flow and decoupling (solid) vs unrealistic heat flow patterns (dashed) from models that do not adequately resolve the mantle wedge flow field (Wada and Wang, 2009).

Figure 10. (a) Initial conditions of a calculation with thickened crustal root showing temperature field (color) and mesh grid (black lines). The upper plate has a depth of $50 \mathrm{~km}$ except for the thickened region, where it extends deeper. The subducting plate is dipping at 20 degrees. The outlined forearc mantle is in magnified view in (b), illustrating the increase in model resolution towards the wedge corner. 
Figure 11. Schematic of thermo-mechanical model setup illustrating the boundary and slab-mantle interface conditions. Arrows in the insets represent velocity fields in decoupled and coupled zones (Modified from Wada and Wang, 2009). 23

Figure 12. Initial conditions and temperature field for 2 different grid resolutions of the simulation at $\mathrm{t}($ time $)=0$. Top: a $10 \times 10$ mesh with grid size $=0.1(N=100)$. Bottom: a $200 \times 200$ mesh with grid size $=0.005(N=$ 40000) 32

Figure 13. Nusselt numbers versus grid size. The grid size has been normalized and is expressed as $\sqrt{ }(1 / \mathrm{N})$, where $\mathrm{N}$ is the total number of grids. For each trial, error bars were calculated based on standard deviation. The blue line is interpolated based on the observed values in black and is interpreted to represent the relationship between grid size and $\mathrm{Nu}$. The Blankenbach benchmark value is shown by the brown dashed line.

Figure 14. Percent error of Nusselt number versus grid size with fitted linear regression models 35

Figure 15. Percent error of Nusselt number versus grid resolution. The grid resolution is expressed as $n X$, where $n X=N$ and $n X=n Y($ number of grids in the $\mathrm{X}$ and $\mathrm{Y}$ direction). Three linear regression models have been fitted to the data. 
Figure 16. Plots of Nusselt number versus elapsed time. Top: grid size $=.04$ (25x25). Bottom: grid size $=.01(100 \times 100)$. While the averages are similar for both simulations: $\mathrm{Nu} \approx 4.90$, the variances in the data are significantly different. 39

Figure 17. Percent Error of Nusselt number versus grid size. The red line is interpolated based on the calculated data points in black. Notice that the error does not necessarily decrease monotonically..... 40

Figure 18. Plots of dynamic pressure for (a) simulation 1: reference case, (b) simulation 2: decoupling no root, (c) simulation 3: thickened root with decoupling, (d) simulation 4: thickened root with decoupling. 44

Figure 19. Plots of vertical velocity $u_{y}$ for (a) simulation 2: decoupling no root, (b) simulation 4: thickened root with decoupling, (c) simulation 6: thinned lithosphere. Velocity vectors are shown as black arrows and their length correspond to the magnitude. Positive velocity is defined as downward. 46

Figure 20. Results of steady-state temperature (pseudocolor), and streamlines (black curves) for corner-flow simulations 1-4 (Table 2) with a stationary over-riding plate and a subducting slab with prescribed motion. Colored contours represent the rate of melt production (volumetric ratio of melt per volume per time) based on Katz et al. (2003) hydrous, adiabatic melting model. (a) Reference case. (b) Identical simulation setup except 
for the inclusion of a thickened crustal root $(15 \mathrm{~km})$ on the over-riding plate. (c) Identical to (a) except for the addition of viscous decoupling by incorporating a low viscosity zone in the forearc slab-mantle interface to a maximum depth of $80 \mathrm{~km}$. (d) Identical to (b) except for the inclusion of

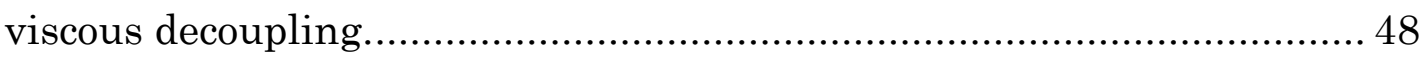

Figure 21. Results of steady-state temperature (pseudocolor), and streamlines (black curves) for corner-flow simulations 5 and 6. (a) Identical to Figure 20d but deeper maximum depth of decoupling $(120 \mathrm{~km})$. (b) Identical to Figure 20d but instead of thickened root, a thinned lithospheric cavity is present

Figure 22. Summary of modeling results showing the variability of melt production defined as volume of melt per surface area per time. A comparison is made for simulations $1-5$.

Figure 23. Summary of modeling results showing the variability of melt production as a function of changing root size. A comparison is made for simulations $2,4,7,8$, and 9 50

Figure 24. Summary of modeling results showing the variability of melt production as a function of changing root size. A comparison is made between simulations 2,4 , and 6 . 51

Figure 25. Differences of melt production rate between thickened root without decoupling (a) and with decoupling (b). Steady-state temperature 
differences of (b) compared to (a) is shown in (c), where regions of positive

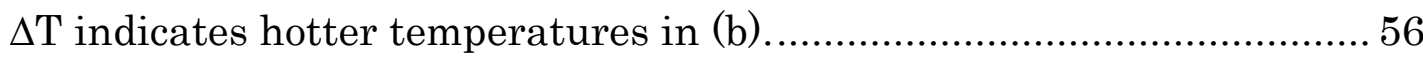

Figure 26: Conceptual model illustrating the changes to mantle melt generation as a result of varying simulation parameters. The over-riding plate consist of the crust (yellow) and the underlying mantle lithosphere (green). Purple stripe represents decoupling layer. (a) Reference case with no decoupling or crustal root with a broad region of melt generation. (b) Presence of a crustal root inhibits flow and produces no arc front melting. (c) Decoupling reduces the radius of corner flow and enables arc front melt production trenchward of the thickened lithosphere. (d) Lithospheric thinning beneath the arc produces greater amounts of mantle melt at shallower depths and shifts the locus of arc front melting landward. 69 


\section{INTRODUCTION}

Subduction zones are major tectonic features that occur along Earth's $\sim 55,000 \mathrm{~km}$ (Lallemand, 1999) of convergent plate margins. Sinking of relatively dense lithosphere provides the main driving force of plate tectonics and delivers oceanic lithosphere, sediments, and seawater to the ambient mantle, triggering melt generation (Hofmann, 1997). Subsequently, subduction zone magmatism forms the continental crust and most ore deposits (Stern, 2002). While plate tectonics provides a framework to understand the role of subduction zones in a broader context, important questions remain regarding the generation and transport of melt and its volcanic surface expression. The dynamic feedback between melt production and crustal evolution as well as the processes that govern the location of partial melting are not well understood.

The mantle wedge is a complex zone of viscous deformation between the overriding plate and subducting slab, which releases water and aids the generation of arc volcanism (van Keken, 2003). The resulting arc front is characterized by a narrow chain of active volcanoes which provide a constraint on the locus of partial melting in the mantle wedge. Traditionally, variation in slab thermal state, defined based on a combination of dip angle, velocity, and age, has been suggested to explain variation in trench-to-arc 
distances observed globally (Syracuse and Abers, 2006). There is an alternative hypothesis for the migration of arc fronts: evolution of the overriding lithosphere. Thickening of the crust due to prolonged magmatism could produce a crustal root, which in turn modifies the mantle wedge flow field, shifting the locus of melting and driving arc front migration (Karlstrom et al., 2014). This model of a thickening crustal root causing arc migration away from trench is consistent with a number of continental arc systems globally, which show covariance between geochemical indices $\left({ }^{87} \mathrm{Sr} / 86 \mathrm{Sr}\right.$, $\mathrm{La} / \mathrm{Yb}$, and bulk silica content) and arc front positions through time.

Wada and Wang (2009) identified the critical role of the weakening of the sub-forearc slab-mantle interface due to the presence of hydrous minerals and high fluid pressure, leading to a decoupled/coupled transition at $\sim 80 \mathrm{~km}$ of depth. This viscous decoupling has implications on partial melting within the mantle wedge. The nose of the wedge below the forearc, closest to the trench, is decoupled from the slab and stagnant. As a result, mantle melting occurs downdip, in the coupled region, with a thermal regime dominated by slab-induced convective wedge flow (Wada et al., 2011).

Previous numerical models of mantle wedge dynamics employ idealized geometries and do not incorporate crustal thickening or viscous decoupling of the slab, nor their effects on melt production (e.g., Davies and Stevenson, 1992; van Keken, 2003; Abers et al., 2006; Wada and Wang, 2009; 
Syracuse et al., 2010). In this study, we incorporate recent structural and petrological observations associated with the Cascadia subduction zone (e.g., Schmandt and Humphreys, 2011; Till et al., 2013; Hopper et al., 2014) to constrain the geometry, thermal, and physical properties of the mantle wedge used in the model. We then use the numerical modeling results to address the following questions: 1) How does lithosphere thickness affect the amount and distribution of melt production? 2) How is this further affected by viscous decoupling of the slab-mantle interface? 


\section{BACKGROUND}

\subsection{Cascadia subduction zone}

Continuous subduction along various parts of the Cascadia margin has been active for at least $200 \mathrm{Myr}$ (Monger and Price, 2002). Trends analogous to modern Cascadia subduction and volcanism began 42-45 Ma, following the accretion of the Siletzia terrane (e.g., Sherrod and Smith, 2000, Schmandt and Humphreys, 2011). Convergence between the subducting Juan de Fuca plate and over-riding North American plate forms the north-south oriented trench (Figure 1). This convergence is oblique, with an azimuth of $\sim \mathrm{N} 61^{\circ} \mathrm{E}$ at $\sim 36 \mathrm{~mm} /$ year determined by HS3-NUVEL1A kinematic model of Gripp and Gordon (2002). The subducting Juan de Fuca slab is relatively young and warm, with an average age of $\sim 8 \mathrm{Ma}$ (Wilson, 1988). Due to its high buoyancy relative to a typical subducting slab, the downgoing Juan de Fuca slab dips at a shallow angle in the mantle below the forearc, approximately 18 degrees based on SLAB 1.0 (Hayes et al., 2012) (Figure 2). Ongoing magmatism due to subduction is responsible for the modern High Cascade arc (e.g., Hildreth, 2007). Melt generation is thought to initiate at relatively shallow depths (40$70 \mathrm{~km}$ ), due to a warm mantle wedge with $1300-1400^{\circ} \mathrm{C}$ of mantle potential temperature (e.g., Elkins Tanton et al., 2001; Lee et al., 2009; Till et al., 2013). 


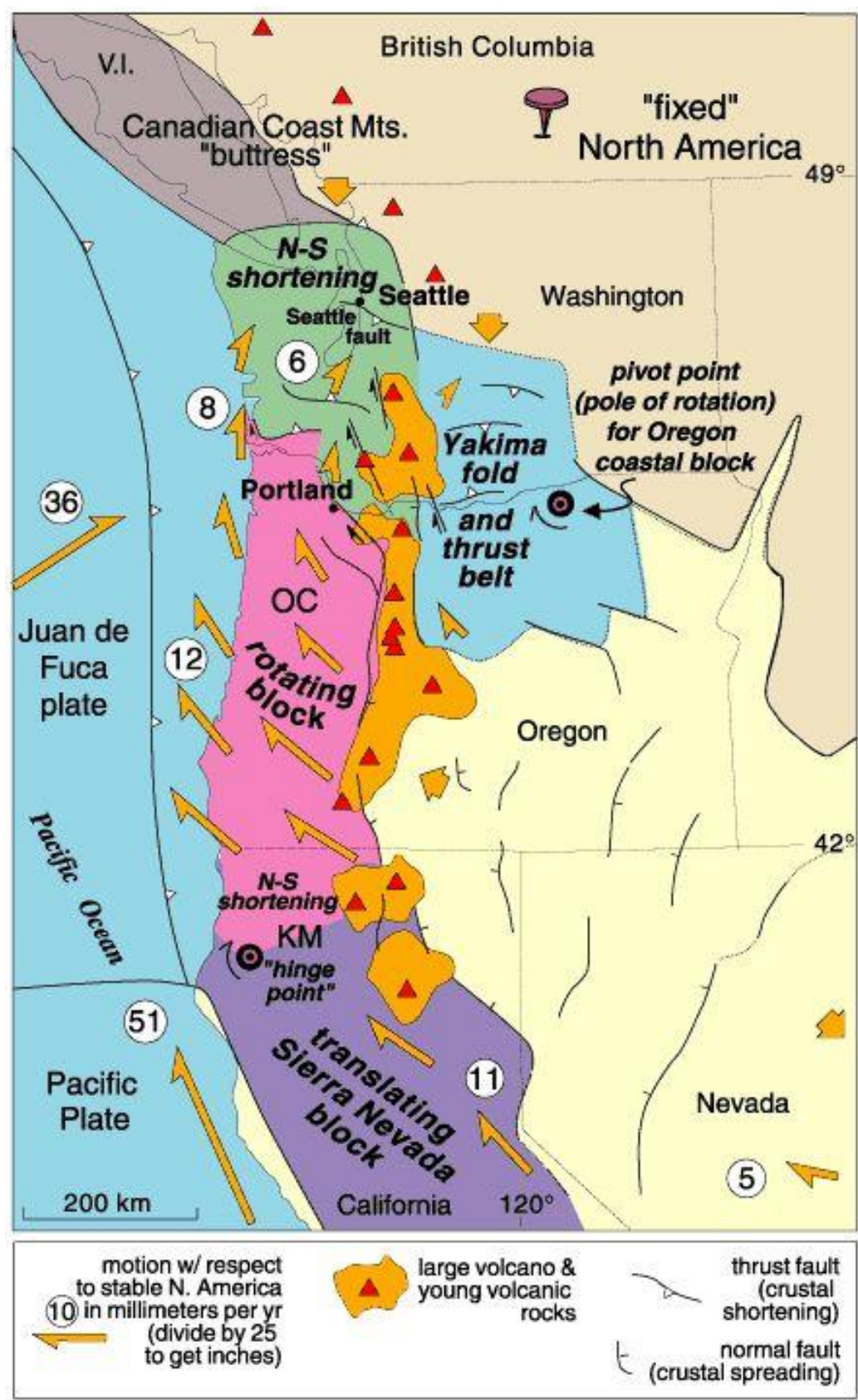

Figure 1. Tectonic setting and GPS velocity vectors of Cascadia subduction zone (Wells et al., 2000). 


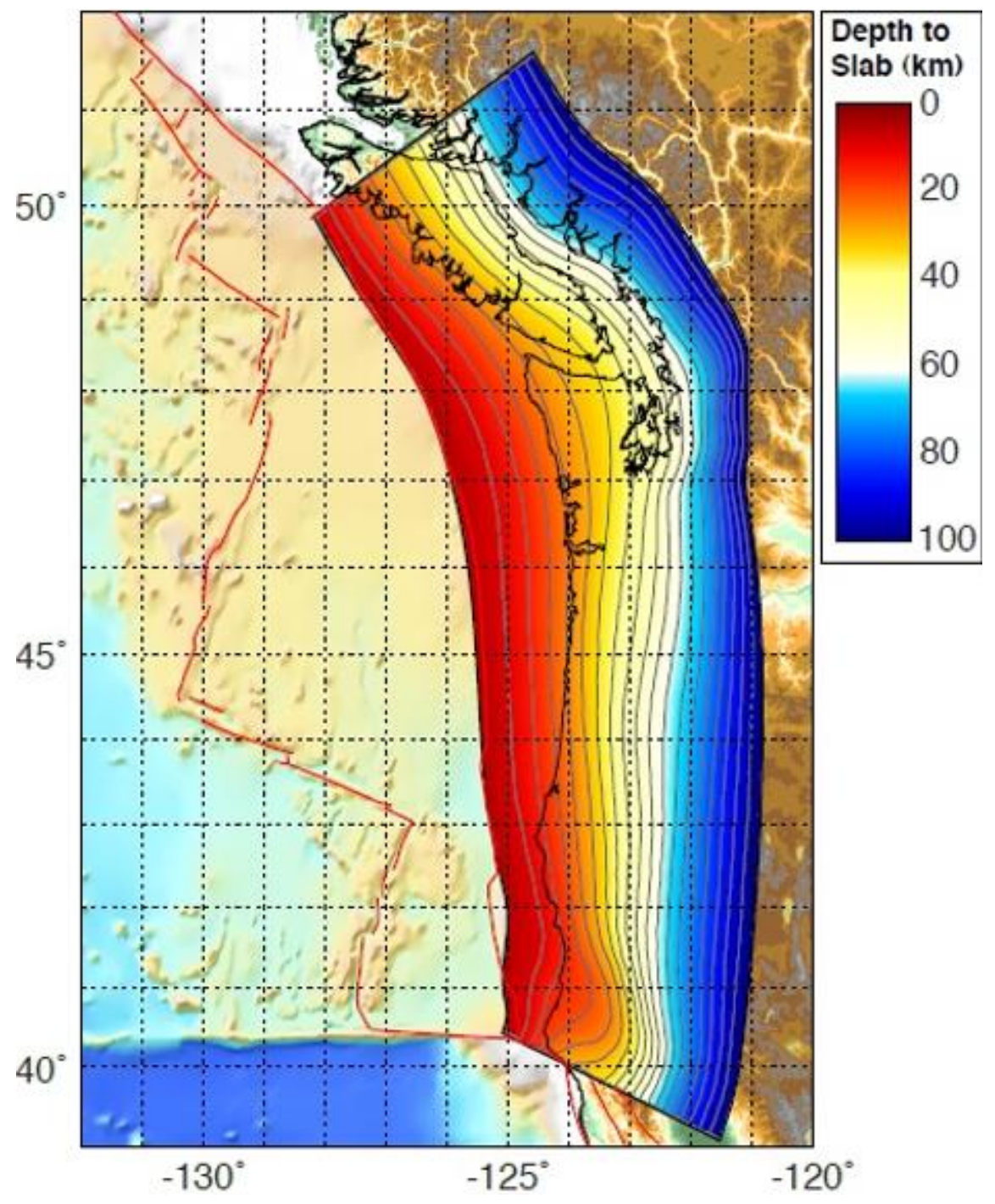

Figure 2. Depth to slab contour map of the Cascadia subduction zone (Hayes elt al., 2012).

\subsection{Melt generation}

Two mechanisms are responsible for partial melting of the mantle wedge in subduction zones. First, hydrous flux melting occurs as the subducting slab undergoes metamorphism and dehydration during descent, 
releasing hydrous phases that lower the peridotite solidus, producing melt (Davies and Stevenson, 1992). Second, adiabatic decompression melting (Figure 3) due to upwellings associated with the small scale convective corner flow in the mantle wedge (e.g. Sisson and Bronto, 1998; England and Katz, 2010). Although both processes are capable of producing mantle melt independently, it is more appropriate to view them as end member scenarios rather than separate or mutually incompatible mechanisms. Global petrologic arc data supports both slab and wedge dominated melting (Turner and Langmuir, 2015). Combined thermomechanical/petrological models demonstrate that decompression melting of the mantle can be important in warm subduction zones (Bouilhol et al., 2015).

Katz et al. (2003) developed an adiabatic melting model for the upper mantle that incorporates the effect of water on the peridotite solidus as a function of temperature and pressure (Figure 4). This parameterization of melt fraction is based on thermodynamic modeling as well as experimental data. It is computationally efficient and widely used, with updates by Langmuir et al. (2006) and Kelly et al. (2010). 


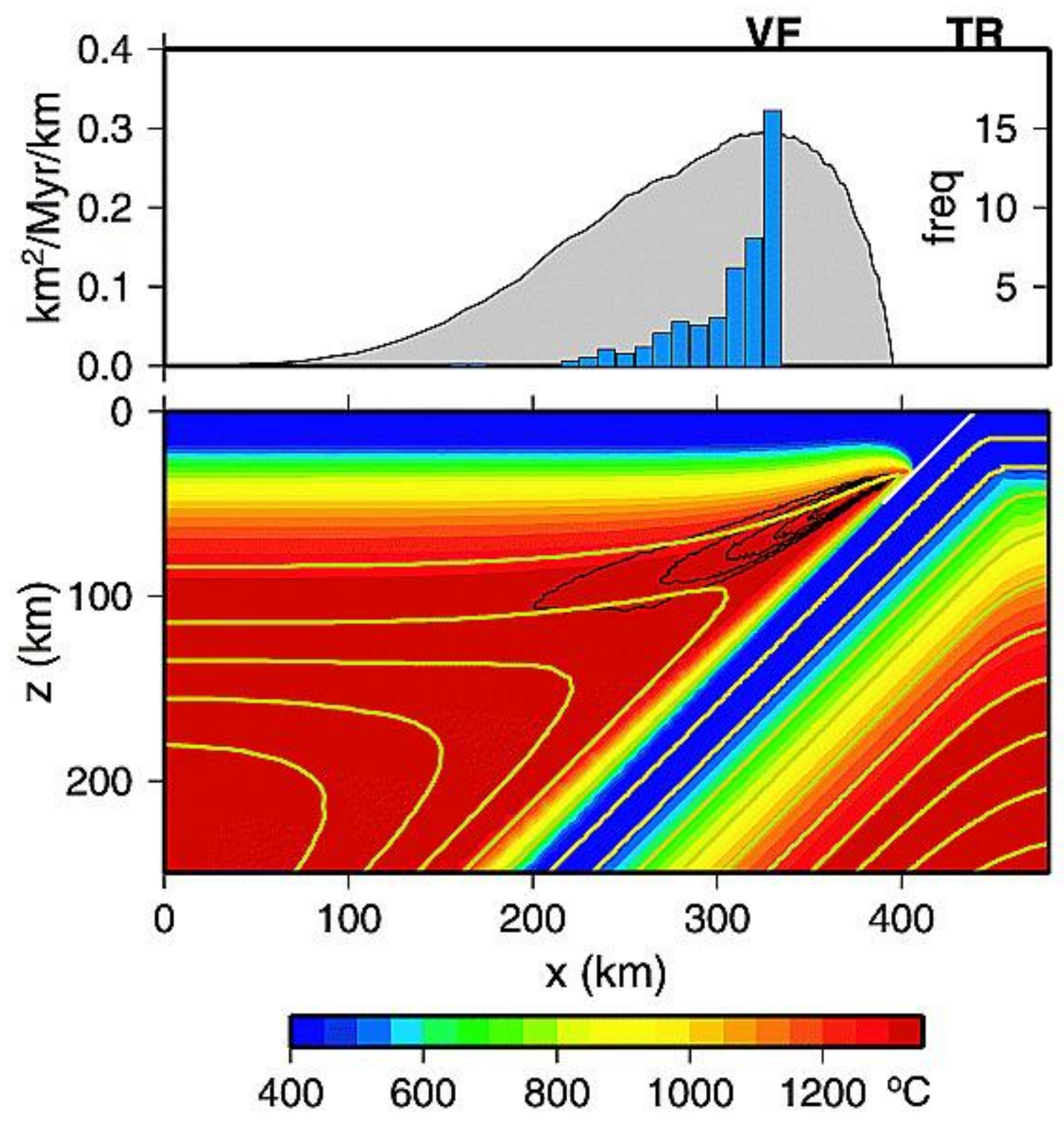

Figure 3. Subduction zone modeling results of temperature, streamlines and decompression melting rate (contours). Upper panel shows the predicted distribution of volcanism(VF) as well as melt production rate along arc length (Conder et al., 2002). 

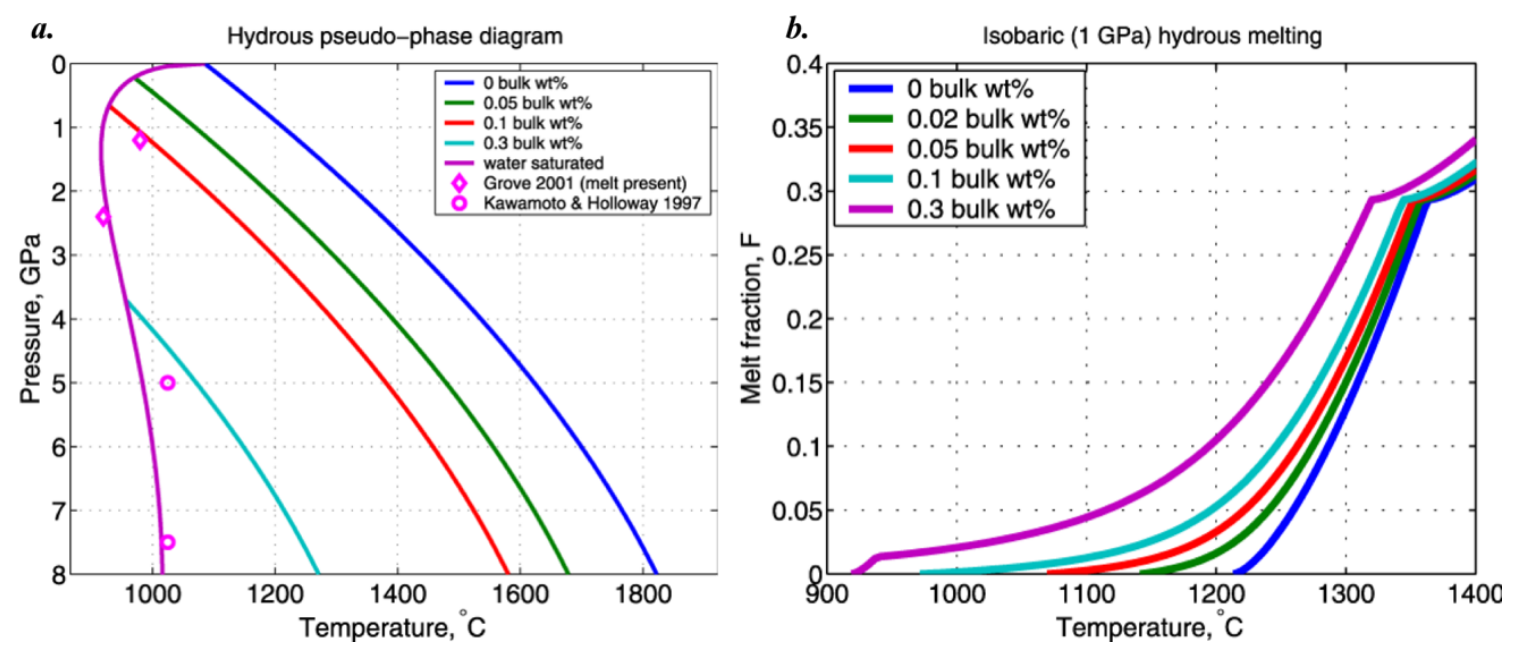

Figure 4. (a) Peridotite solidus for different bulk water contents as a function of temperature and pressure. (b) Isobaric melting curves (1 GPa) showing the effects of temperature on melt fraction (modified from Katz et al., 2003).

\subsection{Crustal thickening}

Changes in crustal thickness can be inferred from surface features. The Airy isostasy model is based on isostatic equilibrium, which states that topography is caused by the density contrast between the relatively light crust and heavy mantle, and is compensated by changes in crustal thickness. In our case, it implies that high topography due to arc magmatism needs to be supported by a thickened crustal root. In the absence of compressional tectonics, thickening of the crust can be achieved in 2 ways: magmatic underplating and overplating. Both processes require the ascent of mantlederived melt through the overlying plate, creating plutons and volcanoes. The locus of this mantle melting has been shown to depend on a combination of slab dip and velocity (England and Katz, 2010). Thickening of the over-riding 
plate beneath volcanic arcs have been proposed for numerous subduction zones based on multiple lines of evidence (e.g., Kay et al., 2005; Chin et al., 2012).

Progressive thickening of the crust throughout the Cascades arc magmatism has been shown based on the petrological evolution of the associated volcanic rocks. Using a compilation of over 4000 geochemical analyses, du Bray and John (2011) identified a temporal trend from the older (>40 Ma), basalt and basaltic andesite magma transitioning to the younger, dacite and rhyolite magma towards $18 \mathrm{Ma}$. In addition, primitive tholeiitic compositions dominated early ( $>25 \mathrm{Ma}$ ) ancestral Cascades, reflecting thin crust and subduction of the spreading center. In contrast, the younger $(<25$ Ma) eruptive products exhibit a more evolved calc-alkaline affinity as well as trace element abundances that are elevated in Sr and lower HREE, characteristic of increased interaction with thickened crust at depths where garnet is stable. Using a decade of USArray Transportable Array data, Shen and Ritzwoller (2016) have created a new tomographic model that jointly inverts data from multiple sources (ambient noise, receiver functions, Rayleigh wave phase velocity and ellipticity from earthquakes). The improved spatial constraint of this model enables the detection of crustal structure beneath the western United States, particularly the Cascadia 
subduction zone. In Figure 5 we show the resulting MOHO depth map for the Cascades, illustrating thickened crust beneath the Cascades volcanic arc.

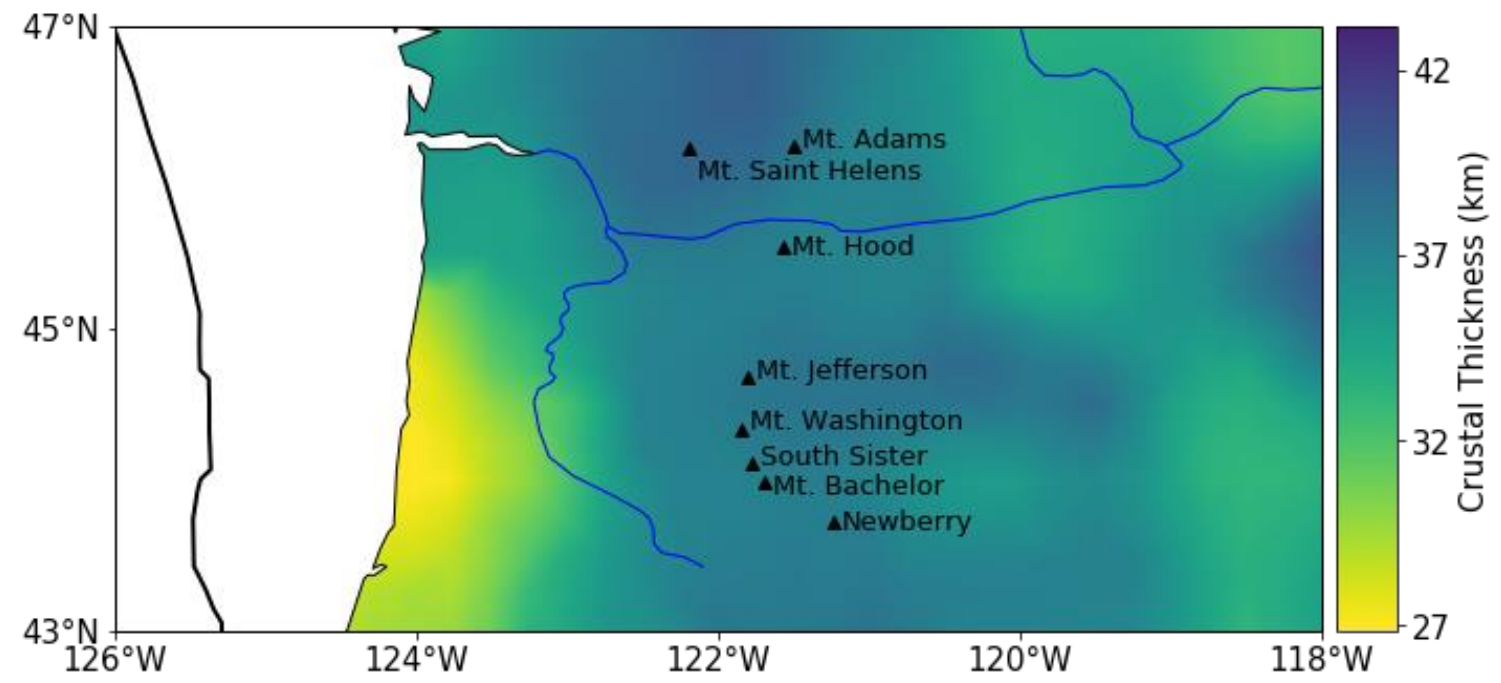

Figure 5. Crustal thickness map of the central Cascadia subduction zone with with major Cascade volcanoes in black triangles. Data taken from Shen and Ritzwoller (2016), based on joint inversion of surface wave dispersion from ambient noise and earthquakes, Rayleigh wave $\mathrm{H} / \mathrm{V}$ ratio, and receiver functions. The subduction trench is shown as bold black line, based on the model of Bird (2003).

\subsection{Arc front migration}

The configuration of most subduction zones is fairly uniform in that the arc front is typically located along a narrow zone where the depth of the descending slab is $\sim 100 \mathrm{~km}$ (England et al., 2004). The traditional interpretation of arc front migration is that changes in slab dip angle with time will shift the distance of the active volcanic front to the trench (Dickinson and Snyder, 1978). Globally, most arcs show a systematic relationship between the distance from trench to arc front and thermal 
parameters that control the wedge geometry (England and Wilkins, 2004, Syracuse and Abers, 2006). It has been shown that the same parameters (slab age, convergence rate and dip angle) correlate with major element geochemistry of arc rocks, which record the interactions from mantle melt to the surface (Plank and Langmuir, 1988). Therefore, the location of the arc front can be controlled by temperature dependent processes occurring within the mantle wedge (England and Wilkins, 2004).

Alternatively, changes in the overriding plate have also been proposed to drive arc front migration. There is an observed eastward migration of the Cascades arc since $45 \mathrm{Ma}$ (du Bray and John, 2011) (Figure 6). GPS measurements of modern plate motion and structural mapping has been used to argue that rigid crustal blocks on the Western margin of North America has experienced clockwise rotation about a fixed pole over the last $\sim 40 \mathrm{Myr}$ (Wells and McCaffrey, 2013) (Figure 1). In this case the dextral component from the oblique convergence of the subducting Juan de Fuca plate causes the crustal blocks to decouple from the fixed underlying mantle, causing apparent migration of the Cascades arc.

This study explores a third hypothesis: thickening of the overlying plate causes arc front migration (Karlstrom et al., 2014). Thickening of crust creates a root that may alter the temperature, pressure, and velocity fields in the underlying mantle wedge. These changes potentially impact magma 
transport and differentiation, due to the interactions with an evolving upper plate. A number of geochemical indices for continental arcs are shown to covary with spatial migration of the arc moving away from trench through time (Figure 7). As arcs migrate away from the trench, increases in isotopic ratio ${ }^{87} \mathrm{Sr} / 86 \mathrm{Sr}$ as well as bulk silica content suggest greater crustal transit and storage. An increase in trace element ratio $\mathrm{La} / \mathrm{Yb}$ is used to monitor changing residual mineralogies towards the higher pressure, garnet stability field, interpreted to indicate thickening of the crust (Lee et al., 2007). 


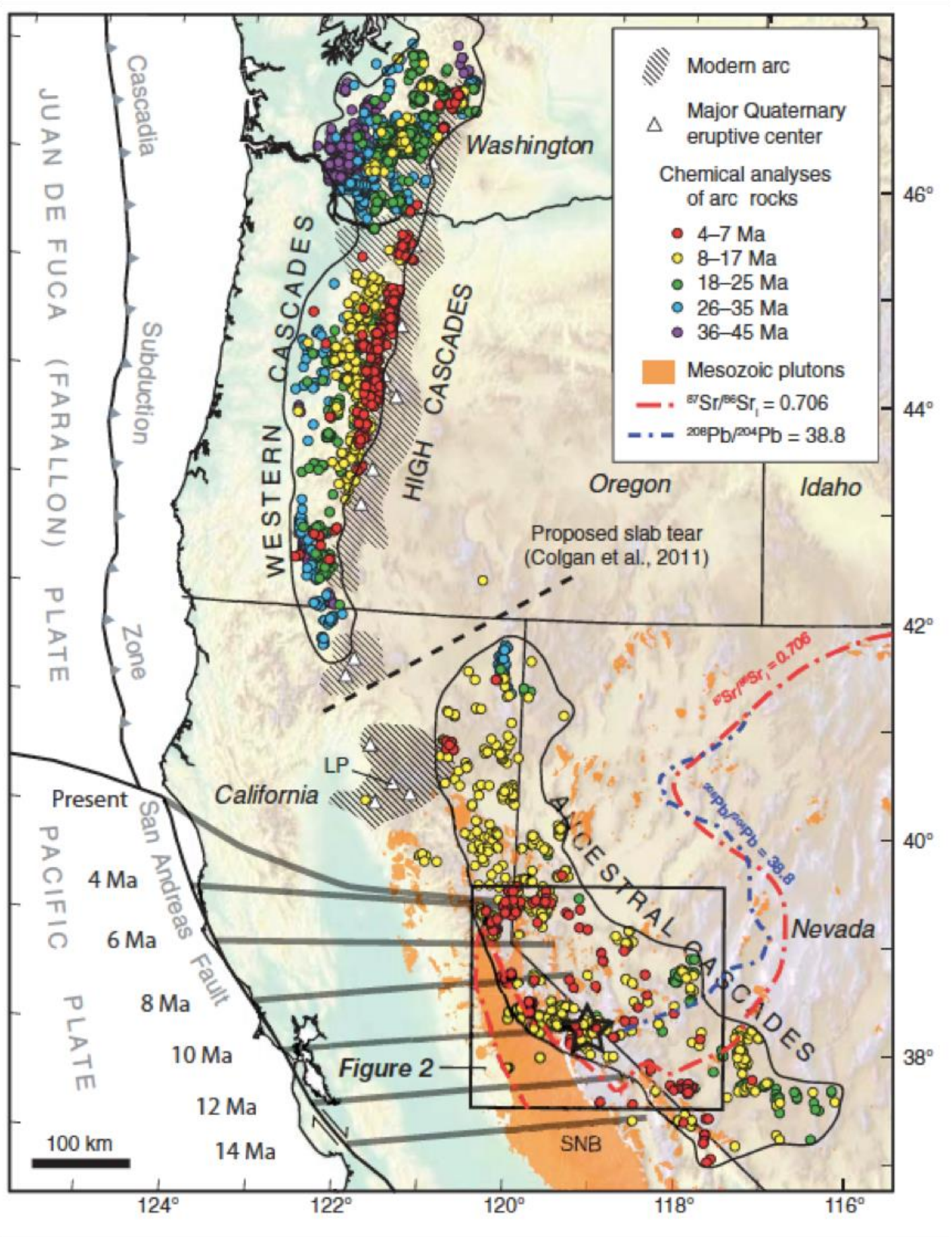

Figure 6. Map showing the locations of dated Western Cascade deposits along the west coast. From John et al. (2012). 


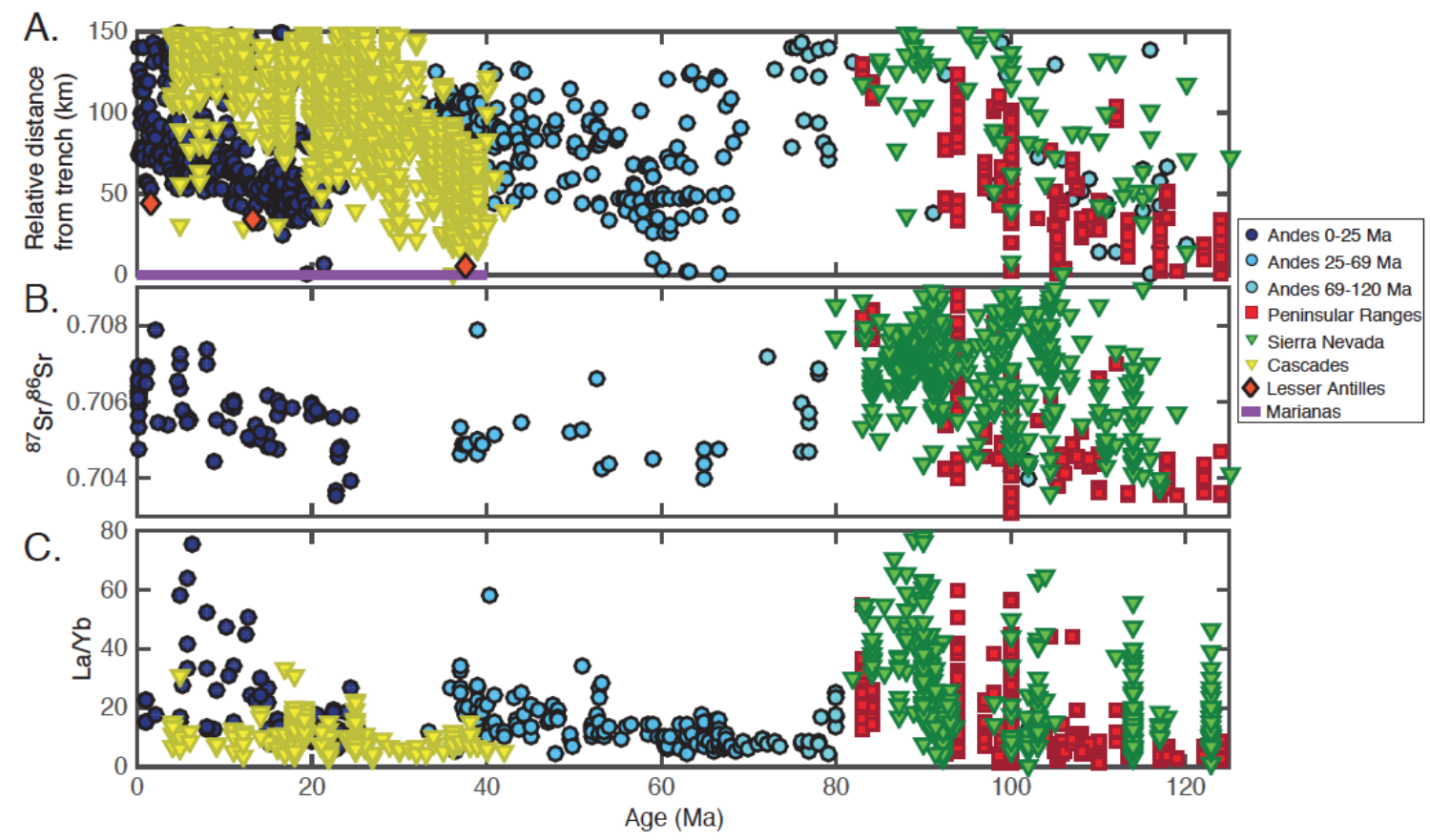

Figure 7. Global compilation of continental and oceanic arc data. (A) Ages of igneous rocks and relative distances to the trench. (B) Initial ${ }^{87} \mathrm{Sr} / 86 \mathrm{Sr}$ isotopic ratio and $(\mathrm{C})$ ratio of trace elements $\mathrm{La} / \mathrm{Yb}$. (modified from Karlstrom et al., 2014)

\subsection{Viscous decoupling of the slab-mantle interface}

The interaction between the subducting slab and over-riding mantle varies within the mantle wedge. Beneath the volcanic arc and back-arc, flow in the mantle wedge is driven by the downdip motion of the subducting slab. In contrast, the sub-forearc mantle may be decoupled and stagnant relative to the downgoing slab (Wada et al., 2008). There are several lines of evidence which support this dichotomy. Surface heat flow decreases from the trench landward, remains low in the forearc region, and then increases to high 
values at the arc and back-arc. Currie and Hyndman (2006) suggests this cold "nose" in the mantle wedge is the result of conductive cooling of the subducting slab while thermal convection by solid-state viscous flow is responsible for hot upper mantle below the arc and back-arc.

Serpentinization of the forearc mantle has been proposed for several places including Cascadia (Bostock et al., 2002; Brocher et al., 2003) based on low seismic velocities and is supported by seismic tomography (Ramachandran et al., 2005) as well as positive magnetic and negative gravity anomalies (Blakely et al., 2005). Several studies show a sharp contrast between low seismic attenuation in the forearc and high attenuation in the sub-arc upper mantle, indicating a stagnant forearc mantle wedge with low temperatures (e.g., Tsumura et al., 2000; Wiens and Smith, 2003; Stachnik et al., 2004; Abers et al., 2006). As part of the iMUSH project, active-source seismic data indicate Mount St Helens sits atop a serpentinized mantle wedge (Hansen et al., 2016) (Figure 8). The inferred presence of serpentine in the forearc mantle signifies a hydrated, cold mantle with temperatures below $700^{\circ} \mathrm{C}$ (Hyndman and Peacock, 2003). Earthquakes located within the forearc mantle wedge is also consistent with low temperatures required for seismic rupture (e.g., Hasegawa et al., 1994; Nakajima et al., 2001; Miura et al., 2003). 


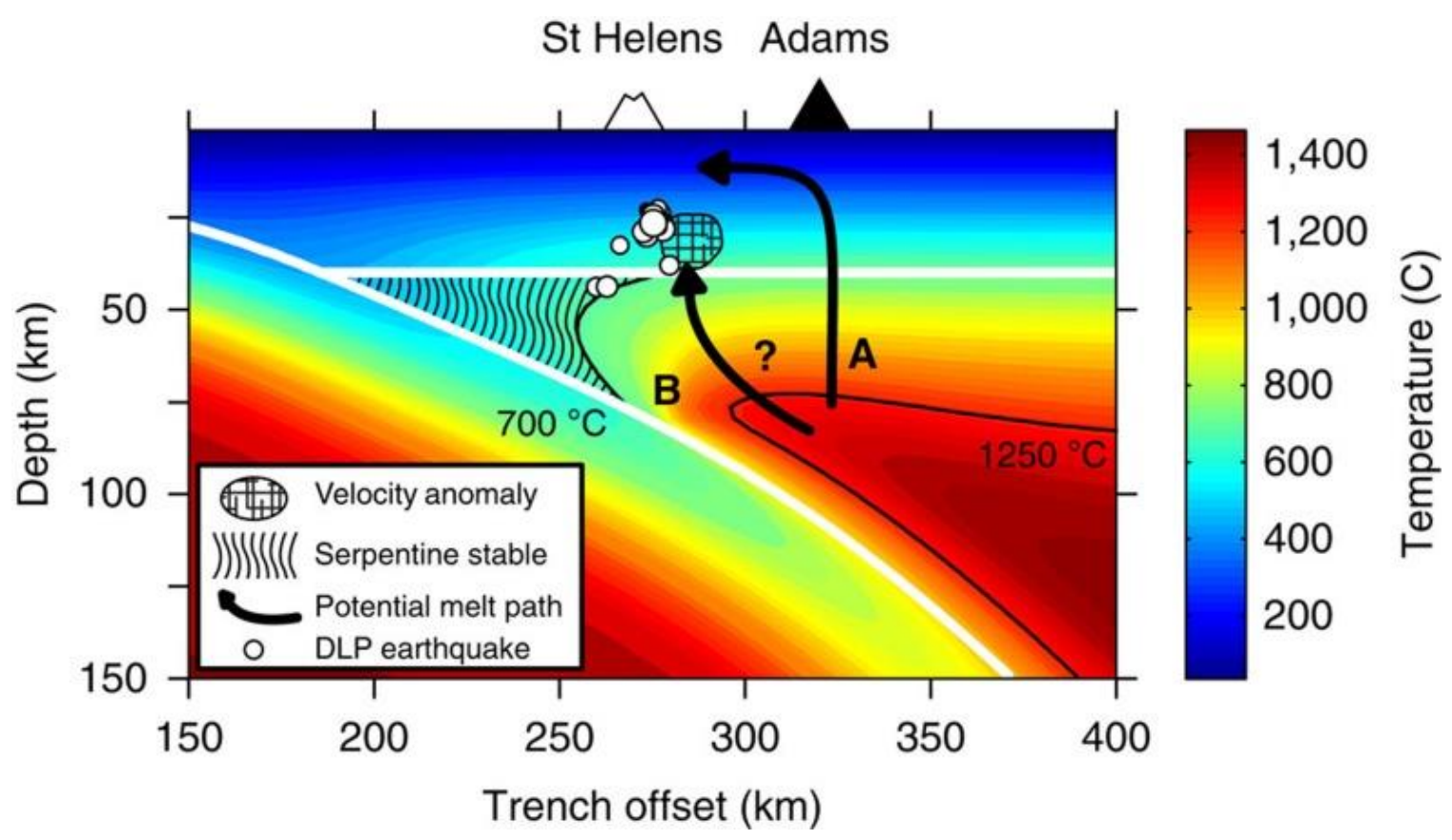

Figure 8. Thermal model of the Cascadia subduction zone showing the serpentinized forearc at the cold corner of the mantle wedge (Hansen et al., 2016).

For the forearc corner of the mantle wedge to become stagnant, decoupling of the slab and overlying mantle is necessary (Furukawa, 1993). A feedback mechanism of this decoupling plate interface involves high fluid pressure, hydrous minerals, and cooling effect of the slab (Peacock and Hyndman, 1999; Wada et al., 2008). The landward transition from the decoupled sub-forearc slab and mantle into the coupled sub-arc slab and mantle is abrupt (Figure 9). Wada and Wang (2009) concluded that a common maximum depth of decoupling (MDD) of $\sim 80 \mathrm{~km}$ is consistent with heat flow constraints and the observed similarity of arcs situated along narrow zones where the depth of the dipping slab is approximately $100 \mathrm{~km}$ for most 
subduction zones. This viscous decoupling has implications for partial melting within the mantle wedge: the nose of the wedge below the forearc, close to the trench, is decoupled from the slab and stagnant; thus mantle melting occurs downdip in the coupled region, with a thermal regime dominated by slab induced convective wedge flow (Wada et al., 2011).

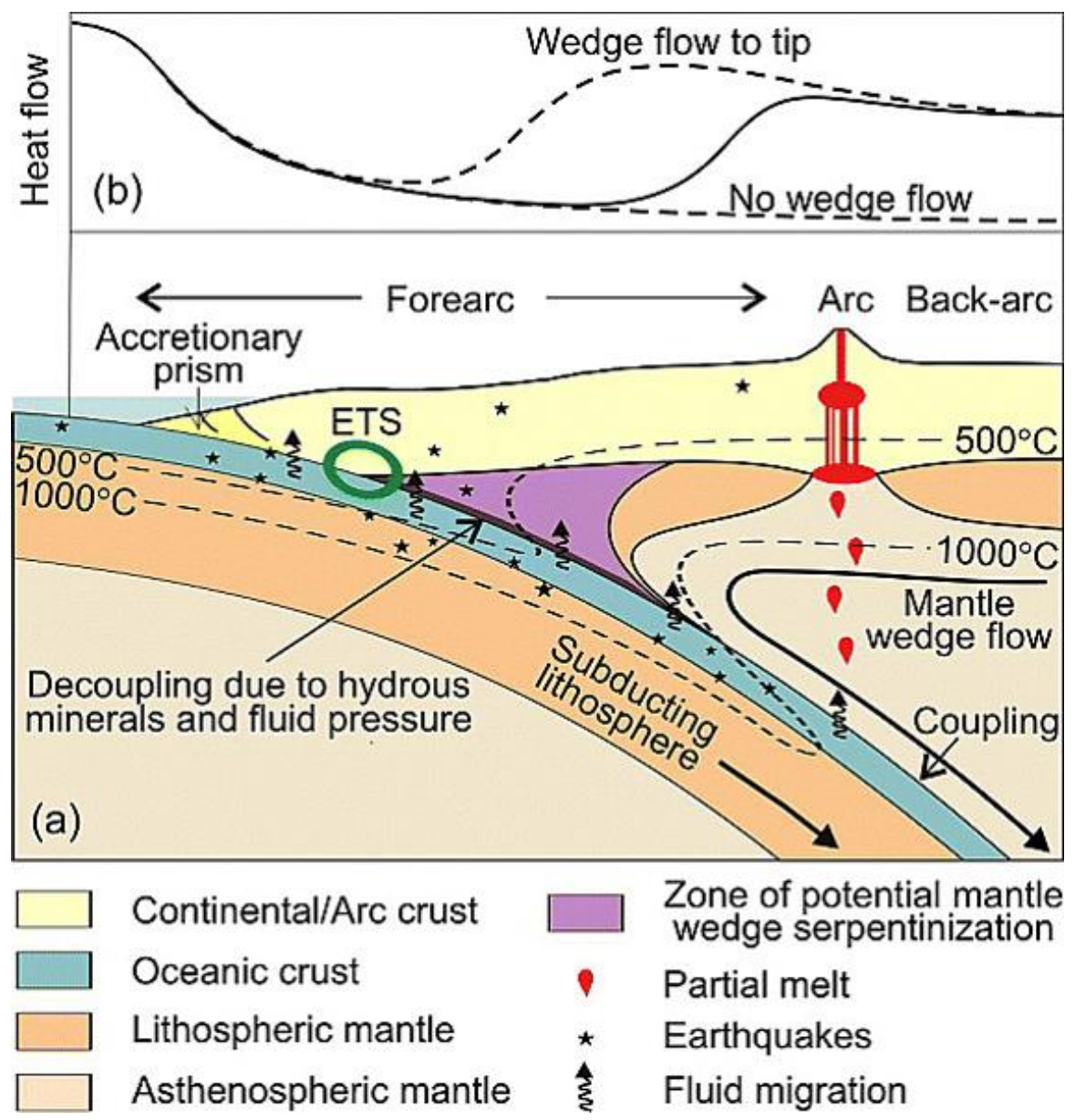

Figure 9. (a) Idealized cross-section of an ocean-continent warm-slab subduction zone analogous to Cascadia, illustrating slab-mantle interactions and processes that occur in the mantle wedge. Green circle represents region of non-volcanic episodic tremor and slip. (b) Surface heat flow curve incorporating wedge flow and decoupling (solid) vs unrealistic heat flow patterns (dashed) from models that do not adequately resolve the mantle wedge flow field (Wada and Wang, 2009). 


\section{$3 \quad$ METHODS}

\subsection{Numerical methods}

Using a numerical modeling approach, we simulated mantle melt production in the Cascadia subduction zone with parameters constrained by recent seismic, geochemical, and surface observations. The kinematic corner flow model is modified from a $2 \mathrm{D}$ finite volume thermo-mechanical convection model which solves the time-dependent advection-diffusion equation for energy:

$$
\rho C_{p} \frac{D T}{D t}=\nabla \cdot(k \nabla T)+H
$$

where $\rho$ is density, $C_{p}$ is heat capacity, $k$ is thermal conductivity, and $H$ is volumetric heat production, $\frac{D T}{D t}$ is the substantive time derivative of temperature corresponding to the standard Lagrangian-Eulerian relation, such that

$$
\frac{D T}{D t}=\frac{\partial T}{\partial t}+\bar{u} \cdot \operatorname{grad}(T)
$$

for our case in $2 \mathrm{D}$ :

$$
\frac{D T}{D t}=\frac{\partial T}{\partial t}+u_{x} \cdot \frac{\partial T}{\partial x}+u_{y} \cdot \frac{\partial T}{\partial y}
$$

where $\bar{u}$ is velocity. 
We also solve the stokes equations for an incompressible, variable viscosity fluid. The conservation of momentum:

$$
\nabla \cdot \overline{\overline{\sigma^{D}}}-\nabla P+\rho \bar{g}=0
$$

where $\overline{\overline{\sigma^{D}}}$ is the deviatoric stress tensor, $P$ is pressure, and $\bar{g}$ is gravity.

The continuity equation for the conservation of mass:

$$
\nabla \cdot \bar{u}=0
$$

The constitutive equation for viscous friction:

$$
\overline{\overline{\sigma^{D}}}=2 \eta \overline{\bar{\epsilon}^{D}}
$$

where $\eta$ is the dynamic viscosity, and $\overline{\bar{\epsilon}}^{D}$ is the deviatoric strain rate tensor.

The subduction model implements the above numerical solutions for the governing equations using the methods described in Gerya and Yuen (2003). Incorporating the parameters in Table 1, the numerical model uses a finite volume technique with marker-in-cell approach based on the method outlined in Gerya and Yuen (2007). The code is written in the C programming language and uses the PETSc library (Balay et all., 2014) for parallelization, management of data structures, and access to scalable solvers. The solutions to the governing equations are a system of linear equations that were solved using the parallel direct solver MUMPS (Amestoy et al., 2001, 2006).

The corner flow model calculates pressure, velocity and temperature structures of the subduction zone mantle wedge and consists of a stationary 
over-riding plate, a kinematically prescribed subducting slab with fixed geometry and velocity, and an isoviscous mantle wedge in which melt production is to be calculated (Figure 11). The calculations were performed on a non-uniform mesh grid, such that the greatest resolution is focused at the nose of the mantle wedge, where solutions are expected to change most rapidly. Each cell of the grid is assigned 12 Lagrangian markers, in each the vertical and horizontal directions. Excess markers were eliminated if more than 1000 were present in one cell using the method described by Leng and Zhong (2011) and additional markers were added (using nearest-neighbor interpolation) to any cell quadrant without any markers. Each individual simulation took $\sim 200$ hours of run time to reach statistical steady-state. 

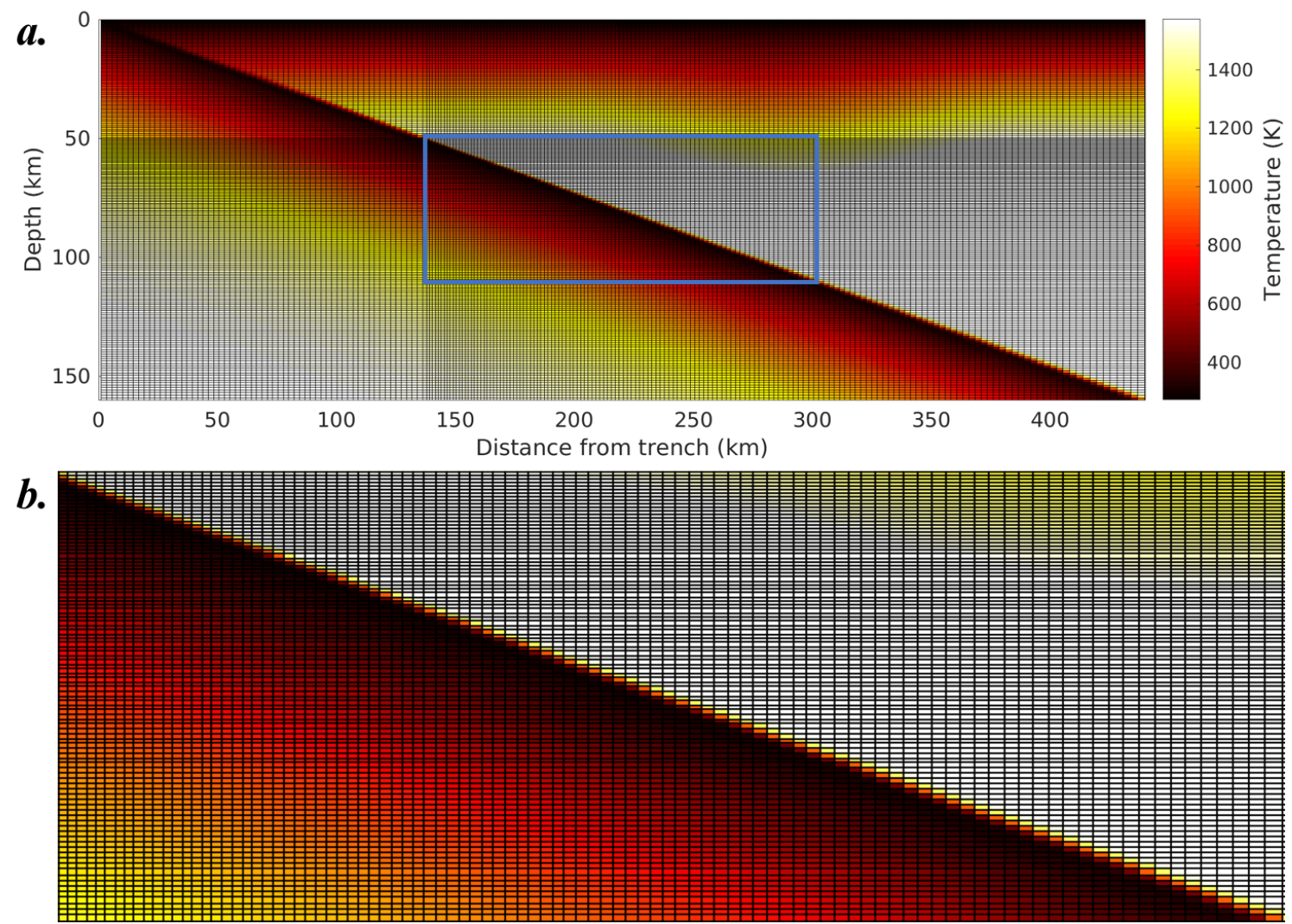

Figure 10. (a) Initial conditions of a calculation with thickened crustal root showing temperature field (color) and mesh grid (black lines). The upper plate has a depth of $50 \mathrm{~km}$ except for the thickened region, where it extends deeper. The subducting plate is dipping at 20 degrees. The outlined forearc mantle is in magnified view in (b), illustrating the increase in model resolution towards the wedge corner.

\subsubsection{Boundary conditions}

A schematic of the thermo-mechanical subduction model setup is shown in Figure 11, illustrating the boundary conditions and slab-mantle interface interactions. We investigate the effects of viscous decoupling by enforcing a $4 \mathrm{~km}$ layer of low viscosity $\left(\eta_{\mathrm{de}}=\eta_{\mathrm{ref}} * 10^{-4}\right)$ along the subduction 
interface above the slab, in a region between the bottom of the over-riding plate to a maximum depth of $80 \mathrm{~km}$ (Wada and Wang, 2009). We also introduce a lower crustal bulge of simplified geometry representing thickened arc root. We analyze the effects of crustal thickening and viscous decoupling based on the numerical steady-state solution via quantitative and qualitative analysis of melt production rate, overall amount, as well as the relative location of melt generation. A full list of simulation runs and their varying differences is summarized in Table 2.

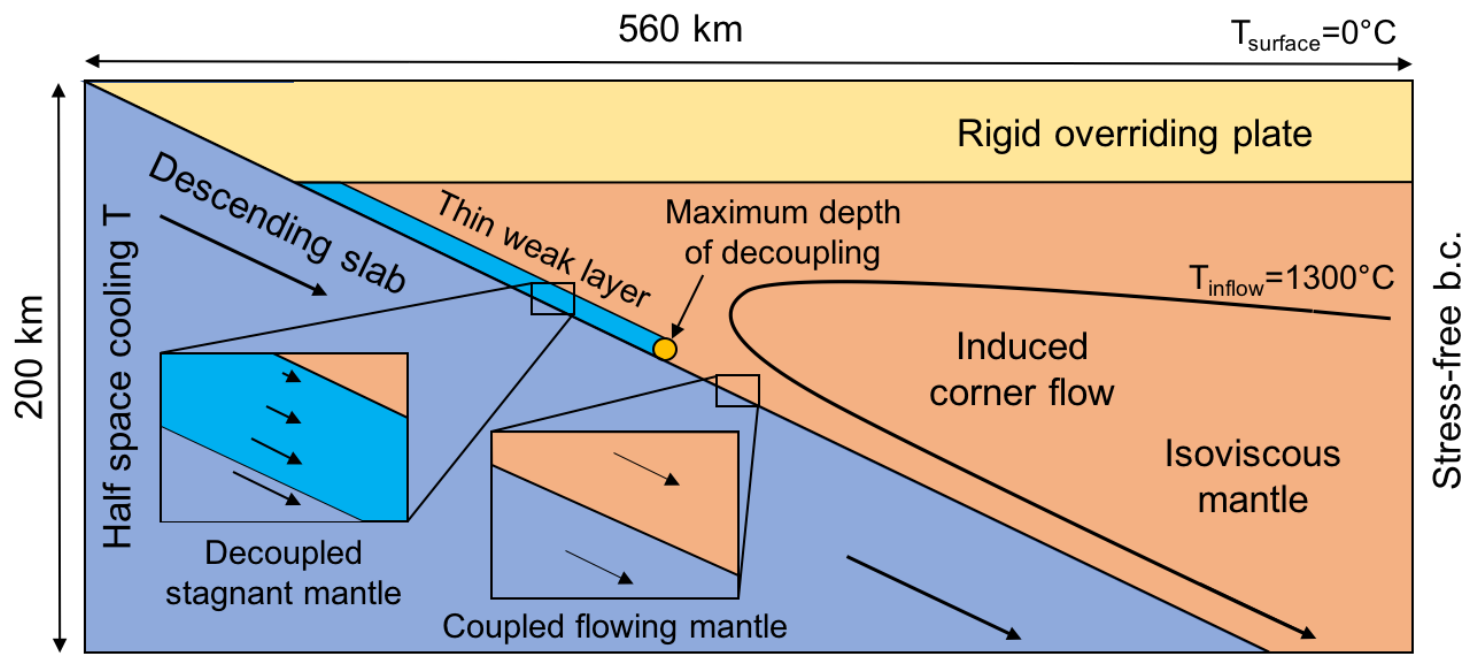

Figure 11. Schematic of thermo-mechanical model setup illustrating the boundary and slab-mantle interface conditions. Arrows in the insets represent velocity fields in decoupled and coupled zones (Modified from Wada and Wang, 2009).

We use the Katz et al. (2003) parameterization for melt fraction as a function of pressure and temperature to model decompression-induced hydrous melting in a wet peridotite mantle with 0.1 bulk wt.\% $\mathrm{H} 2 \mathrm{O}$. Temperature is held at a constant $T_{S}=0^{\circ} \mathrm{C}$ at the surface boundary and $T_{0}=$ 
$1300^{\circ} \mathrm{C}$ at the inflow boundary of the mantle wedge, while a linear geotherm is used for the overriding plate from 0 to $50 \mathrm{~km}$ depth. The temperature at the slab inflow boundary is constrained by an error-function solution for halfspace cooling model for 50 Myr (van Keken et al., 2008):

$$
T(x=0, y)=T_{S}+\left(T_{0}-T_{S}\right) \operatorname{erf}\left(\frac{y}{2 \sqrt{\kappa t_{50}}}\right)
$$

where $t_{50}$ is the age in seconds and $\kappa$ is the thermal diffusivity:

$$
\kappa=\frac{k}{\rho C_{p}}
$$

where $k$ the thermal conductivity, $\rho$ is density, $C_{p}$ is heat capacity listed in Table 1.

\subsubsection{Material models}

The subduction model assumes a homogenous peridotite mantle with typical thermal properties given in Turcotte and Schubert (2004). The rheological constraint of the asthenosphere in the wedge is adopted from Hirth and Kohlstedt (2003), which incorporates the effect of water on reducing the viscosity of the mantle wedge. We use their estimated value of 3 * $10^{19} \mathrm{~Pa}^{*} \mathrm{~s}$, corresponding to a depth of $\sim 100 \mathrm{~km}$ to represent an isoviscous mantle wedge, with the exception of the decoupling weak layer above the forearc region of the subducting slab, where the viscosity is lower by 4 orders 
of magnitude (Wada and Wang, 2009). We set the mantle potential temperature equal to $1300^{\circ} \mathrm{C}$, which represents the lower bound based on the findings of Till et al. (2013), to highlight the effects of decompression-induced wedge melting. There is considerable geophysical and geochemical evidence suggesting a very thin $(5-10 \mathrm{~km})$ mantle lithosphere below the MOHO for the Cascadia subduction zone (e.g., Wagner et al., 2012; Till et al., 2013). Our choice of overriding plate thickness $(50 \mathrm{~km})$ correspond to the LAB depth determined by Levander and Miller (2012), using stacked Ps and Sp receiver functions. The prescribed kinematics of the subducting slab's velocity and dip angle are based on HS3-NUVEL1A (Gripp and Gordon, 2002), and SLAB 1.0 (Hayes et al., 2012), respectively. 
Table 1. Parameters and values used during modeling.

\begin{tabular}{|c|c|c|}
\hline Parameter name & Symbol & Reference Value \\
\hline Model width & 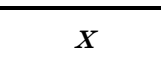 & $5.6 * 10^{5} \mathrm{~m}$ \\
\hline Model depth & $y$ & $2 * 10^{5} \mathrm{~m}$ \\
\hline Number of cells & $N$ & 66264 \\
\hline Initial number of markers per cell & $m$ & 144 \\
\hline Gravitational acceleration & $g$ & $10 \mathrm{~m} \mathrm{~s}^{-2}$ \\
\hline Mantle densitya & $\rho$ & $3300 \mathrm{~kg} \mathrm{~m}^{-3}$ \\
\hline Thermal conductivity ${ }^{\mathrm{a}}$ & $k$ & $3 \mathrm{~W} \mathrm{~m}^{-1} \mathrm{~K}^{-1}$ \\
\hline Heat capacitya & $C_{p}$ & $1250 \mathrm{~J} \mathrm{~kg}^{-1} \mathrm{~K}^{-1}$ \\
\hline Ambient mantle viscosity ${ }^{b}$ & $\eta_{\text {ref }}$ & $3 * 10^{19} \mathrm{~Pa} \mathrm{~s}$ \\
\hline Decoupling weak layer viscosity ${ }^{c}$ & $\eta_{d e}$ & $3 * 10^{15} \mathrm{~Pa} \mathrm{~s}$ \\
\hline Mantle potential temperature & $T_{o}$ & $1300^{\circ} \mathrm{C}$ \\
\hline Surface boundary temperature & $T_{S}$ & $0^{\circ} \mathrm{C}$ \\
\hline Overriding plate thickness ${ }^{\mathrm{e}}$ & $h$ & $5 * 10^{4} \mathrm{~m}$ \\
\hline Slab dip angle ${ }^{f}$ & $\theta$ & $20^{\circ}$ \\
\hline Slab velocity ${ }^{g}$ & V & $36 \mathrm{~mm} \mathrm{yr}^{-1}$ \\
\hline
\end{tabular}

a Turcotte and Schubert, 2004

b Hirth and Kohlstedt, 2003

c Wada and Wang, 2009

d Till et al., 2013

e Levander and Miller, 2012

f Hayes et al., 2012

g Gripp and Gordon, 2002 


\subsubsection{Summary of calculations and varying parameters}

Table 2. Simulation configurations and free parameters used for subduction models.

\begin{tabular}{ccccc}
\hline Simulation id & Description & $\begin{array}{c}\text { Maximum } \\
\text { depth of } \\
\text { decoupling } \\
(\mathrm{km})\end{array}$ & $\begin{array}{c}\text { Thickened } \\
\text { root depth } \\
(\mathrm{km})\end{array}$ & $\begin{array}{c}\text { Thickened }^{\text {root width }} \\
(\mathrm{km})\end{array}$ \\
\hline 1 & reference case & 0 & 0 & 0 \\
2 & decoupling no root & 80 & 0 & 0 \\
3 & thickened root & 0 & 15 & 200 \\
4 & $\begin{array}{c}\text { thickened root w/ } \\
\text { decoupling }\end{array}$ & 80 & 15 & 200 \\
5 & $\begin{array}{c}\text { thickened root } \\
\text { deep decoupling } \\
\text { thinned }\end{array}$ & 120 & 15 & 200 \\
6 & $\begin{array}{c}\text { lithosphere } \\
\text { smallest root }\end{array}$ & 80 & -10 & 100 \\
7 & small root & 80 & 5 & 200 \\
8 & large root & 80 & 10 & 200 \\
9 & . & 20 & 200 \\
\hline
\end{tabular}

a We use a rough approximation to represent the areal extent of the thickened root. The width is estimated from seismic data shown in Figure 5. The varying depths are used to demonstrate the potential differences of root size.

\subsection{Melt calculation}

In order to compute the amount of melt produced, the melt fraction, $F$, must be calculated. In this study, we use the parameterized equations by Katz et al. (2003) to calculate melt fraction:

$$
F=f\left(P, T,{ }^{x} H_{2} O, M_{c p x}\right)
$$


where $F$ is the weight fraction of melt present, $P$ is the pressure in GPa, $T$ is the temperature in degrees Celsius, ${ }^{x} \mathrm{H}_{2} \mathrm{O}$ is weight fraction of water dissolved in the melt and $M_{c p X}$ is the modal CPX of the residual peridotite.

For the purpose of this study, water content and modal CPX is set to representative values given in Katz et al. (2003): ${ }^{\times} H_{2} O=0.1$ wt. $\%$ and $M_{c p x}=$ 17\%. Thus equation 1 simplifies to:

$$
F=f(P, T)
$$

To calculate melt fraction, $F$, a melt fraction lookup table is constructed, which consists of 20 different temperatures, ranging $850^{\circ} \mathrm{C} \leq T \leq 1700^{\circ} \mathrm{C}$, and 40 different pressures, ranging $0.25 \mathrm{GPa} \leq P \leq 10.05 \mathrm{GPa}$. For each combination of temperature and pressure, melt fraction is calculated using Katz et al. (2003) parameterization. Two other quantities, $\frac{\partial F}{\partial P}$ and $\frac{\partial F}{\partial T}$ are also determined numerically using the centered difference scheme. Each simulation is run to statistical steady-state, and the records of temperature and pressure solutions are converted to a regular grid within the model domain. Melt fraction, $F$, as well as $\frac{\partial F}{\partial P}$ and $\frac{\partial F}{\partial T}$ are interpolated based the values in the pre-generated lookup table.

The amount of melt production with time and its spatial variance within the mantle wedge is of particular interest for this study. Since melt fraction, $F$, is a function of pressure, $P$, and temperature, $T$, according to 
equation 2 , using the chain rule, the total derivative of melt fraction, $F$, with respect to time, $t$, is given by the sum of the partial derivatives, such that:

$$
\frac{d F}{d t}=\frac{\partial F}{\partial P} \cdot \frac{d P}{d t}+\frac{\partial F}{\partial T} \cdot \frac{d T}{d t}
$$

The two unknown terms above, $\frac{d P}{d t}$ and $\frac{d T}{d t}$ are calculated using the same Eulerian mesh, such that:

$$
\frac{D P}{D t}=\frac{\partial P}{\partial t}+\vec{u} \cdot \nabla P
$$

similarly,

$$
\frac{D T}{D t}=\frac{\partial T}{\partial t}+\vec{u} \cdot \nabla T
$$

where $\vec{u}$ is the velocity.

The first terms on the right-hand side of equation 12 and $13, \frac{\partial P}{\partial t}$ and $\frac{\partial T}{\partial t}$ represent the changes in pressure and temperature within each element in the Eulerian mesh, and the other terms $\vec{u} \cdot \nabla P$ and $\vec{u} \cdot \nabla T$ represent the gradient of pressure and temperature in or out of the element. Since we are investigating steady-state solutions where the time averaged quantities in the model domain are not changing, we can conveniently set $\frac{\partial P}{\partial t}=\frac{\partial T}{\partial t}=0$. Expanding the second terms on the right-hand side of equation 12 and 13 we get: 


$$
\frac{D P}{D t}=\vec{u}_{x} \cdot \frac{\partial P}{\partial x}+\vec{u}_{y} \cdot \frac{\partial P}{\partial y}
$$

and,

$$
\frac{D T}{D t}=\vec{u}_{x} \cdot \frac{\partial T}{\partial x}+\vec{u}_{y} \cdot \frac{\partial T}{\partial y}
$$

where $\vec{u}_{x}$ and $\vec{u}_{y}$ are velocities in the $\mathrm{x}$ and y direction, respectively.

Finally the rate of melt production, $\frac{d F}{d t}$, for a given simulation at steady-state can be determined using equation 11 by combining the interpolated results using the lookup table $\left(\frac{\partial F}{\partial P}, \frac{\partial F}{\partial T}\right)$ and the solutions $\left(\frac{D P}{D t}, \frac{D T}{D t}\right)$ from equation 14 and 15:

$$
\frac{d F}{d t}=\frac{\partial F}{\partial P}\left(\vec{u}_{x} \cdot \frac{\partial P}{\partial x}+\vec{u}_{y} \cdot \frac{\partial P}{\partial y}\right)+\frac{\partial F}{\partial T}\left(\vec{u}_{x} \cdot \frac{\partial T}{\partial x}+\vec{u}_{y} \cdot \frac{\partial T}{\partial y}\right)
$$

All post-processing calculations are done using MATLAB scripts.

\subsection{Model benchmark and resolution tests}

To model a process using finite-difference methods, one of the first steps is the discretization of the continuous solution space, so that a continuous function can be evaluated by a finite number of approximations on a grid (Slingerland and Kump, 2011). Choosing the appropriate resolution for the meshgrid can be a tricky task. Accuracy of solutions increase with smaller grid size, but so does simulation duration (Iserlas 2008). The tradeoff 
between accuracy and computation time requires the determination of a practical grid size so that a simulation completes in a reasonable amount of time while obtaining acceptable data accuracy. I determined the minimum grid resolution needed in order to obtain a Nusselt number solution within $1 \%$ error for an idealized thermal convection simulation using the $2 \mathrm{D}$ finite volume convection model outlined above.

\subsubsection{Methods}

I reproduced thermal convection case 1a (steady convection with constant viscosity in a square box where the Raleigh number $\mathrm{Ra}=10^{4}$ ) outlined in Blankenbach et al., (1989). 12 different square grids where chosen with normalized grid sizes ranging from 0.005 to 0.1 (Figure 12). For each grid size a simulation was ran until it reached steady-state, and the Nusselt number $(\mathrm{Nu})$ was calculated as a time-averaged value using MATLAB according to Blankenbach et al. (1989) definition:

$$
N u=-h \frac{\int_{0}^{1} \partial_{z} T(x, z=h) d x}{\int_{0}^{1} T(x, z=0) d x}
$$

where $h$ is the height of the cell $\left(10^{6} \mathrm{~m}\right), x$ is the horizontal coordinate, $z$ is the vertical coordinate, and $T$ is temperature. 

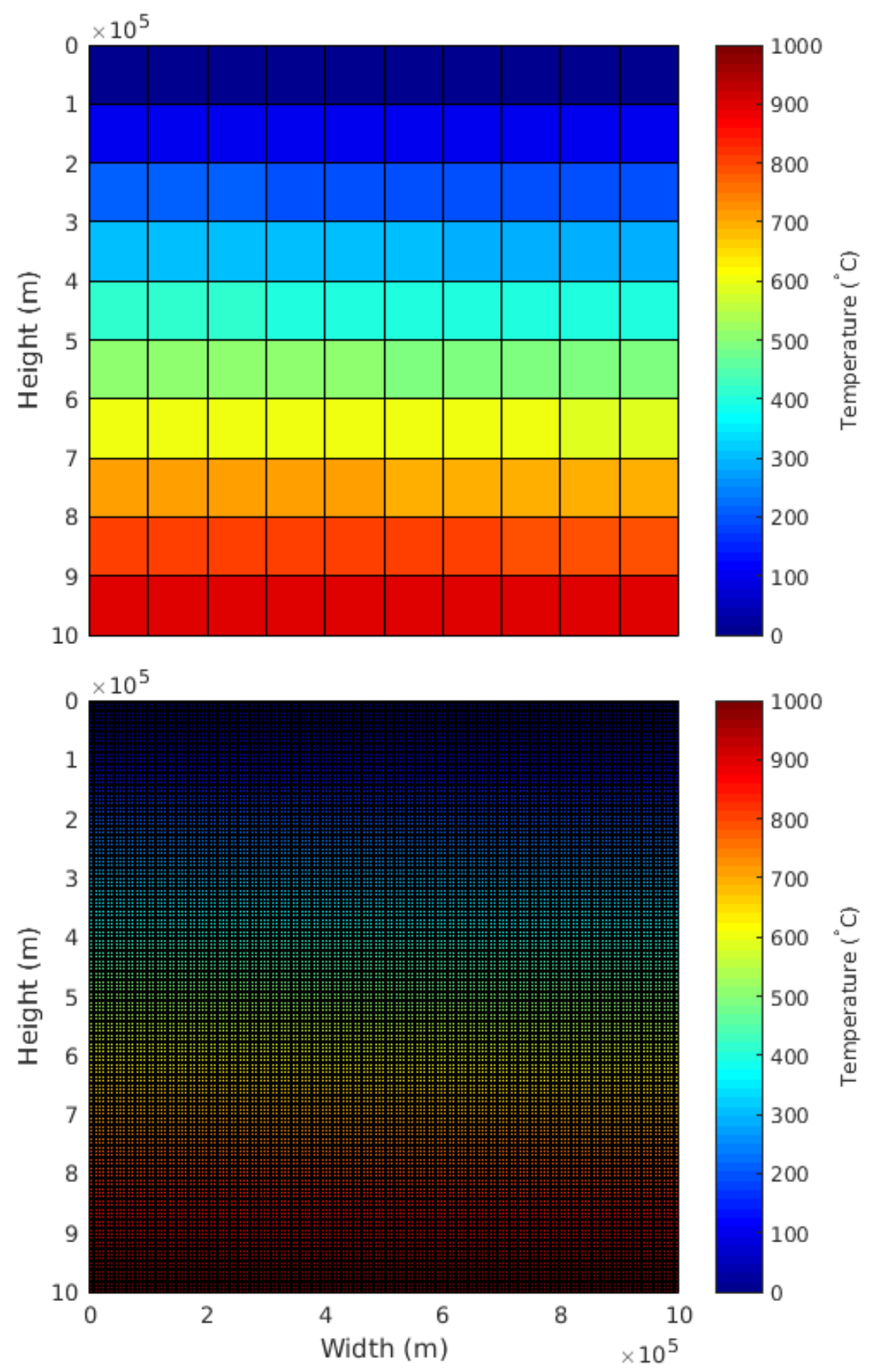

Figure 12. Initial conditions and temperature field for 2 different grid resolutions of the simulation at $\mathrm{t}($ time $)=0$. Top: a 10x10 mesh with grid size $=0.1(\mathrm{~N}=100)$. Bottom: a 200x200 mesh with grid size $=0.005(\mathrm{~N}=40000)$. 
To determine the accuracy of the simulations, comparisons were made between the calculated Nusselt number and the benchmark value $(\mathrm{Nu}=$ 4.884409) for different grid sizes. There exists a small uncertainty of 0.00001 in the benchmark value but we can safely use the benchmark $\mathrm{Nu}$ as the expected value. For each trial, percent difference was calculated to represent error. Finally, several regression schemes were fitted and statistically tested in order to determine any linear relationship between grid size and error.

\subsubsection{Results}

Table 3. Different grid resolution and Nusselt number solutions for thermal convection case 1a (Blankenbach et al. 1989). Percent Error was calculated using benchmark as the expected value. Standard deviation was given because the Nusselt number was calculated as a time-averaged value at steady-state.

\begin{tabular}{cccc}
\hline $\begin{array}{c}\text { Grid } \\
\text { Resolution }\end{array}$ & Pusselt Number & $\begin{array}{c}\text { Percent } \\
\text { Error }\end{array}$ & Standard Deviation \\
\hline $10 \times 10$ & 4.050800 & 17.066736 & 0.034596 \\
$12 \times 12$ & 4.395927 & 10.000842 & 0.022065 \\
$14 \times 14$ & 4.604439 & 5.731921 & 0.020491 \\
$16 \times 16$ & 4.737702 & 3.003585 & 0.033746 \\
$20 \times 20$ & 4.848993 & 0.725076 & 0.019027 \\
$25 \times 25$ & 4.899000 & 0.298724 & 0.028431 \\
$36 \times 36$ & 4.923315 & 0.796531 & 0.013149 \\
$50 \times 50$ & 4.919536 & 0.719161 & 0.012227 \\
$75 \times 75$ & 4.905188 & 0.425421 & 0.007351 \\
$100 \times 100$ & 4.897150 & 0.260851 & 0.005275 \\
$150 \times 150$ & 4.888036 & 0.003627 & 0.005030 \\
$200 \times 200$ & 4.884020 & 0.007960 & 0.003182 \\
Benchmark & 4.884409 & 0.000000 & 0.000010 \\
\hline
\end{tabular}




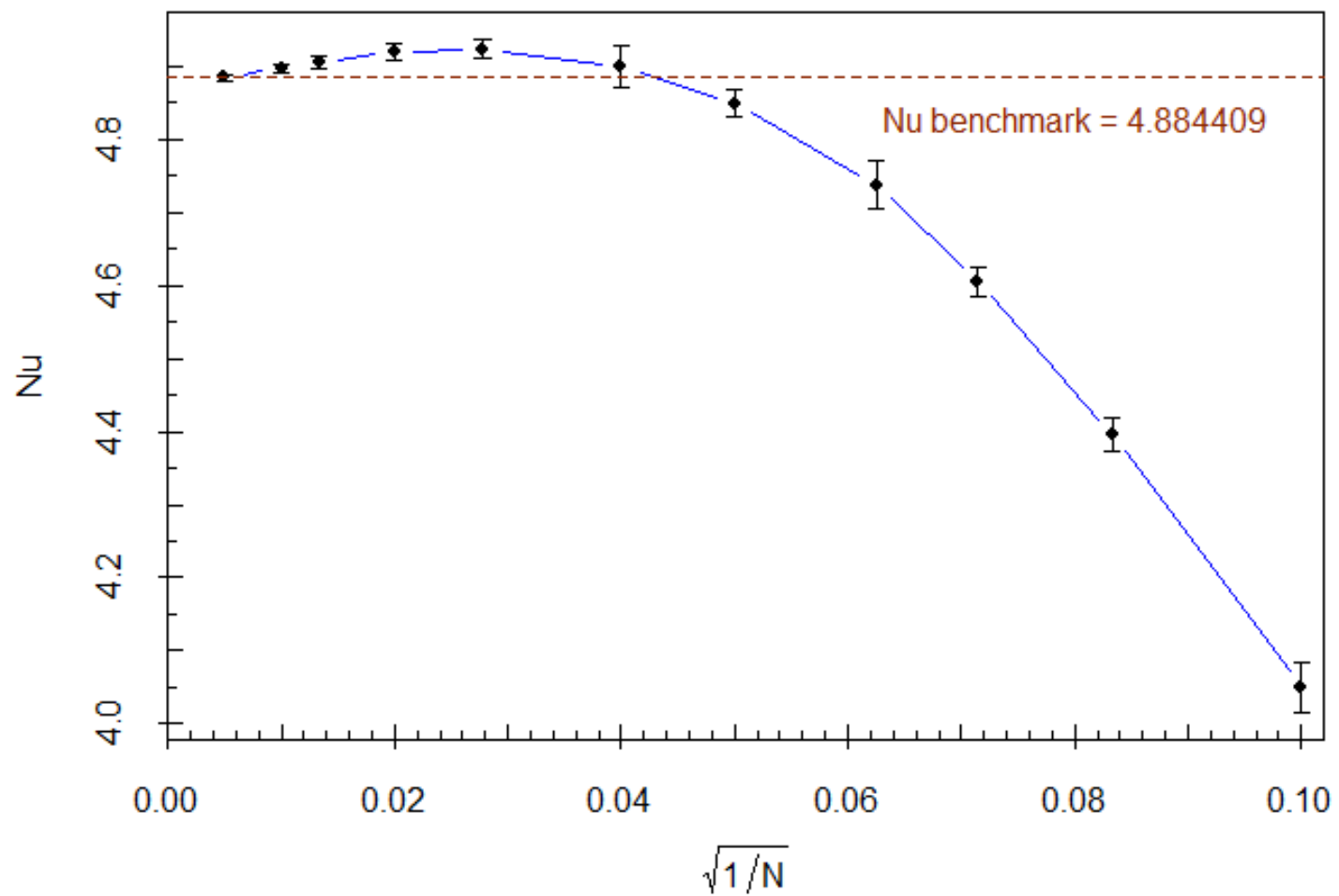

Figure 13. Nusselt numbers versus grid size. The grid size has been normalized and is expressed as $\sqrt{ }(1 / \mathrm{N})$, where $\mathrm{N}$ is the total number of grids. For each trial, error bars were calculated based on standard deviation. The blue line is interpolated based on the observed values in black and is interpreted to represent the relationship between grid size and $\mathrm{Nu}$. The Blankenbach benchmark value is shown by the brown dashed line. 


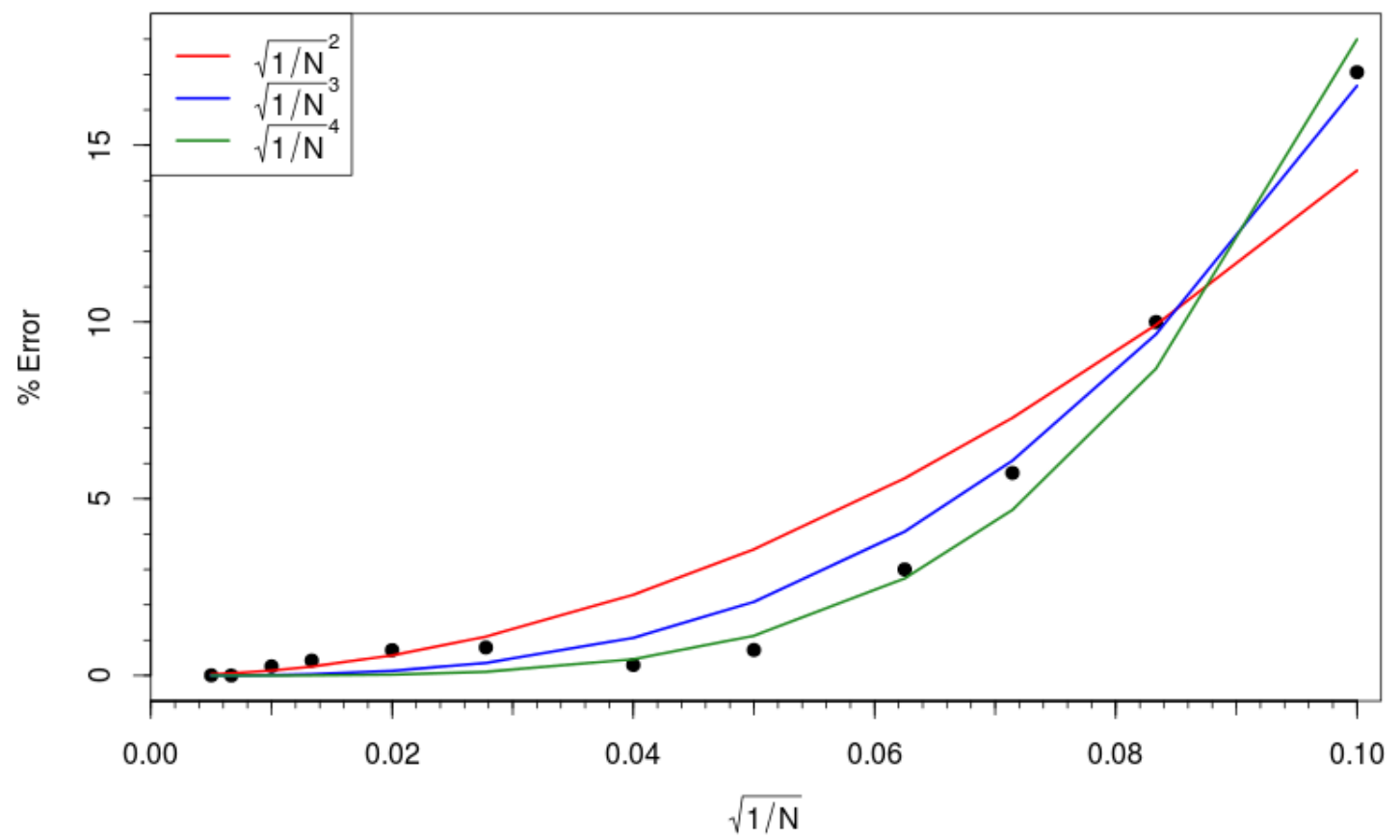

Figure 14. Percent error of Nusselt number versus grid size with fitted linear regression models.

Table 4. ANOVA results for the 3 fitted models shown in Figure 14.

\begin{tabular}{llrcrr}
\hline Model & & $\begin{array}{c}\text { Sum of } \\
\text { Squares }\end{array}$ & $\begin{array}{c}\text { Degrees of } \\
\text { Freedom }\end{array}$ & $\begin{array}{c}\text { Mean } \\
\text { Squares }\end{array}$ & F-Tests \\
\hline Second & Regression & 406.17 & 1 & 406.17 & 153.98 \\
degree & Residual & 29.02 & 11 & 2.64 & \\
& Total & 435.19 & 12 & 408.81 & \\
Third & Regression & 430.46 & 1 & 430.46 & 1003.70 \\
degree & Residual & 4.72 & 11 & 0.43 & \\
& Total & 435.18 & 12 & 430.89 & \\
Fourth & Regression & 430.03 & 1 & 430.03 & 917.36 \\
degree & Residual & 5.16 & 11 & 0.47 & \\
& Total & 435.19 & 12 & 430.50 & \\
\hline
\end{tabular}




\subsubsection{Discussion}

\subsubsection{Error decreases very rapidly as grid size decreases.}

As expected, discretization error plays a key role in determining the magnitude of Nusselt number error with varying grid sizes. Smaller grid sizes yield less discretization error, which in turn improves the accuracy of the simulation. However, error improves at a rate much faster than grid size reduction: the percent error decreases rapidly from $17 \%$ to less than $1 \%$ as mesh resolution increases from 10x10 to $25 \times 25$ (Figure 12). While the fit for all three models are statistically significant: F-statistic greater than the table value (4.844, $\alpha=0.05)$; the third degree regression model is the best fit because it has the largest F-statistic value (Table 4). Therefore, the relationship between percent error and grid size can be approximated by the third degree

regression model: Error $=\mathrm{C} \sqrt{1 / \mathrm{N}}^{3}$. For example, if grid size is reduced by $1 / 2$, the percent error is expected to decrease by a factor of 8 . 


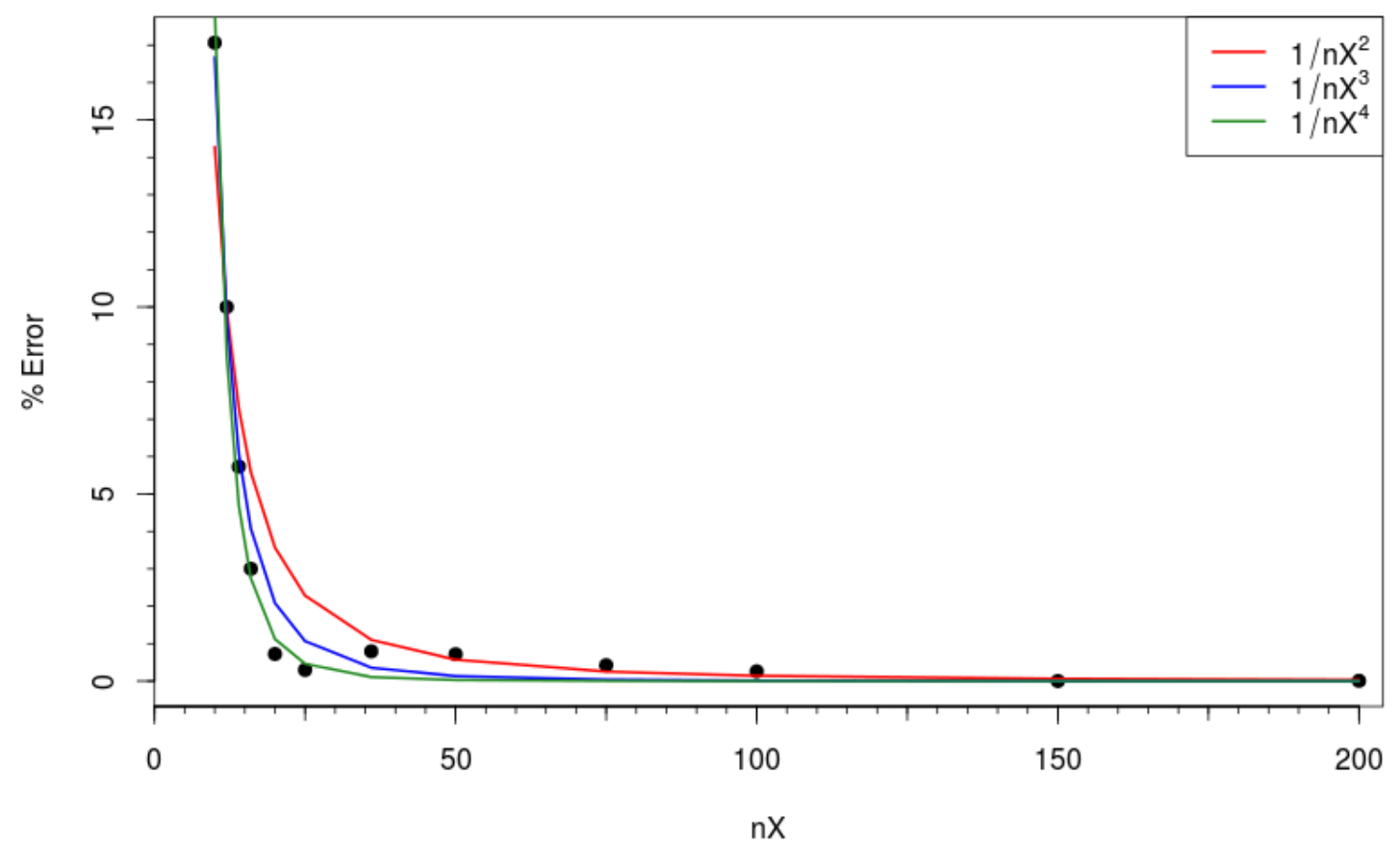

Figure 15. Percent error of Nusselt number versus grid resolution. The grid resolution is expressed as $n X$, where $n X=\sqrt{N}$ and $n X=n Y$ (number of grids in the $\mathrm{X}$ and $\mathrm{Y}$ direction). Three linear regression models have been fitted to the data.

3.3.3.2 Variance of steady-state solution decreases with decreasing grid size.

While the data used in this study were obtained from simulations in steady-state, the simulations are not strictly "unchanging in time". There exists some variance in the steady-state solution as shown in Figure 13. Due to this variance, a time-averaged Nusselt number and standard deviation of 
the steady-state solution were calculated for each simulation. It is not surprising to find that the standard deviation of the Nusselt number decreases as grid size decreases (Table 4). I suspect that the reduction in discretization error with smaller grid size is responsible for the relative uniformity of the steady-state solution. It's also interesting to note that while the means of the data are very similar for $25 \times 25$ and $100 \times 100$, the variance significantly improves with smaller grid size (Figure 16). 

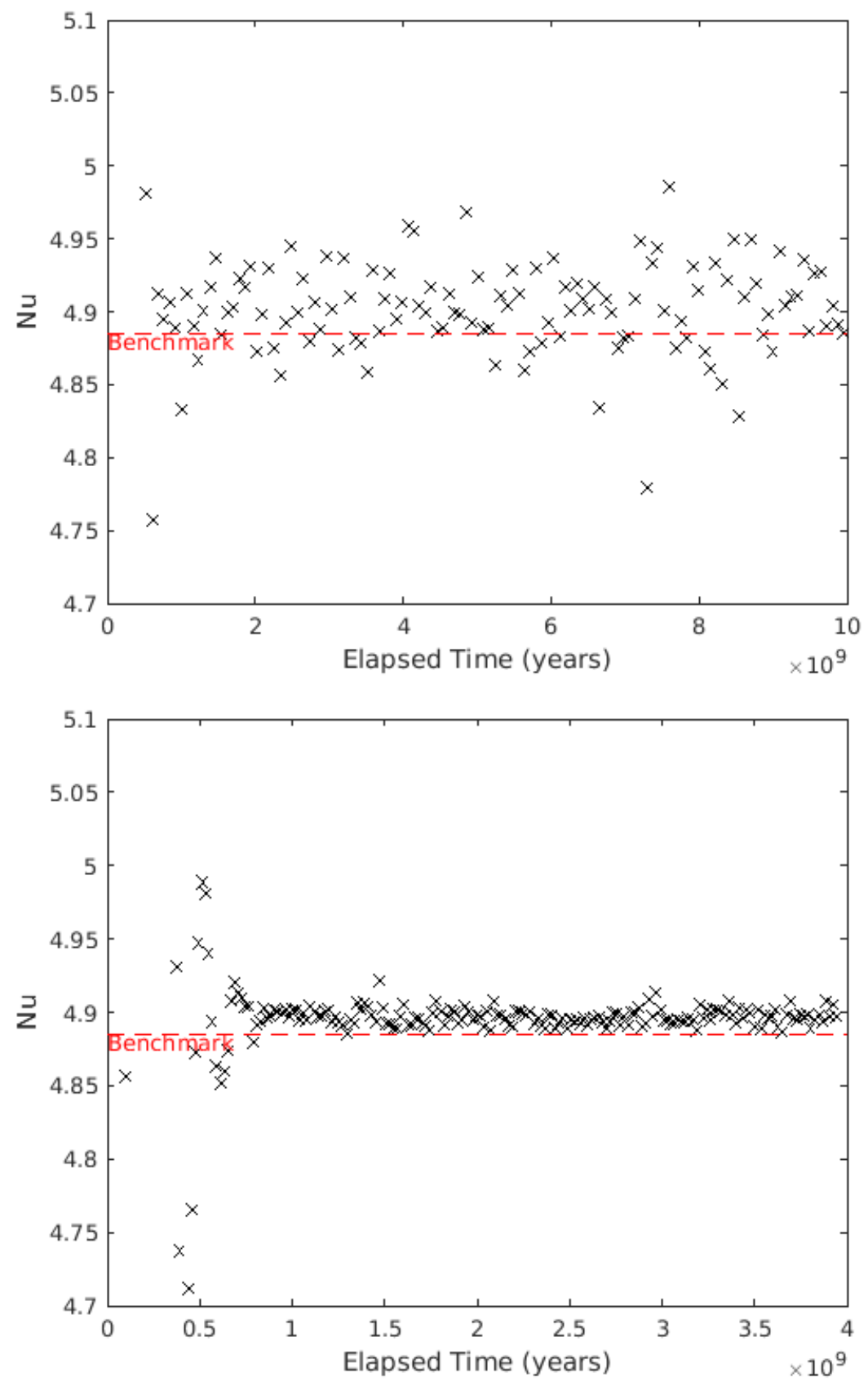

Figure 16. Plots of Nusselt number versus elapsed time. Top: grid size $=.04$ $(25 \times 25)$. Bottom: grid size $=.01(100 \times 100)$. While the averages are similar for both simulations: $\mathrm{Nu} \approx 4.90$, the variances in the data are significantly different. 


\subsubsection{Accuracy increases with decreasing grid size, but not}

monotonically.

One interesting observation to note is that the error behavior is not always monotonic with respect to grid size. Notice the decreasing trend in error as grid size decreases with the exception of an increase from grid size 0.04 to 0.02 (Figure 17). This is a rather puzzling and unexpected finding. There exist variances in the time-averaged Nusselt numbers, but it isn't large enough to explain the reversal of the error trend. At this time I lack a satisfactory explanation for the phenomenon.

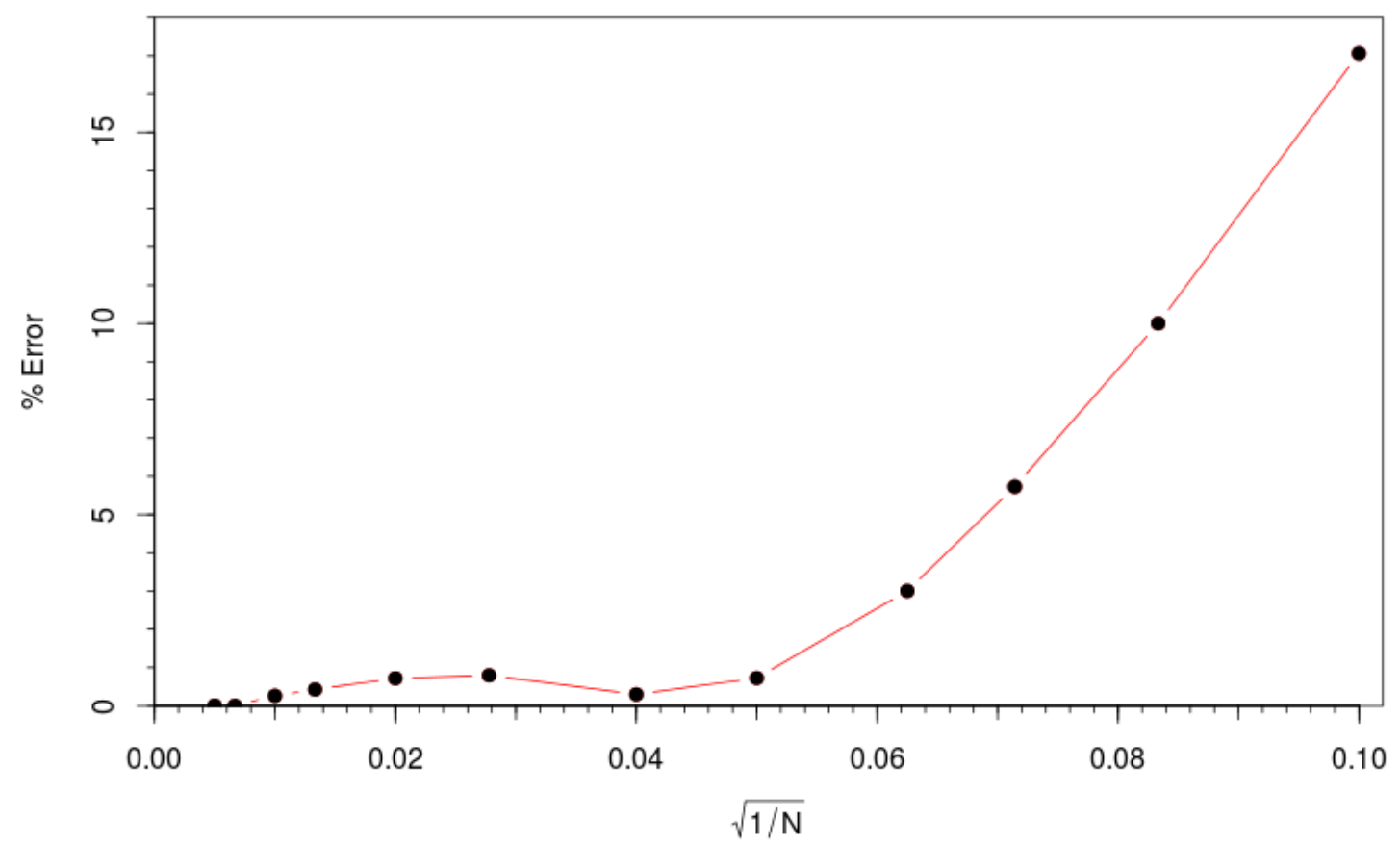

Figure 17. Percent Error of Nusselt number versus grid size. The red line is interpolated based on the calculated data points in black. Notice that the error does not necessarily decrease monotonically. 


\subsubsection{Conclusions}

Based on the numerical simulation results and error analysis, the finite volume convection model used is capable of producing benchmark values of the Nusselt number. Obtaining a Nusselt number solution within $1 \%$ error requires a minimum resolution is $25 \times 25$, a normalized grid size of 0.04 or less. This is a lower limit as convergence of steady-state solutions continue to improve with better resolution. We've shown that the finite volume code used is capable of reproducing steady convection benchmarks, it is important to note that there exist considerable differences in the model setup between $2 \mathrm{~d}$ convection and subduction corner flow. However, the corner flow model has been previously verified to reproduce benchmark values from van Keken et al. (2008), where the thermal structure and dynamics of subduction zones are constrained using a suite of numerical models. 


\section{RESULTS}

In this section, we present the simulation results from our various

configurations of modeling experiments (Table 2). The effects of thickened crust and decoupled mantle are shown to include the pressure, flow and temperature in the mantle wedge. In turn, the magnitude and distribution of melt production are affected accordingly.

\subsection{Dynamic pressure}

The first order observation from the steady-state dynamic pressure field is that negative pressure associated with the mantle flow increases towards the corner of the mantle wedge (Figure 18). In addition, our results also verify O'Driscoll et al. (2009) claim that a thickened crustal root protruding into the asthenosphere decreases the overall pressure (the sum of positive lithostatic pressure and negative dynamic pressure) by enhancing the magnitude negative pressure in the mantle wedge. On the other hand, viscous decoupling reduces the magnitude of dynamic pressure. Together, crustal thickening and viscous decoupling have competing effects on dynamic pressure, though they affect slightly different regions due to differences in their relative spatial extent. For the particular set of models in Figure 18, the thickened crust induces a broader influence directly under the root, whereas 
the reduction of dynamic pressure from viscous decoupling is seen at the tip of the mantle wedge above the decoupled zone. The net torque exerted on the slab due to "suction" of the negative dynamic pressure is shown in . 


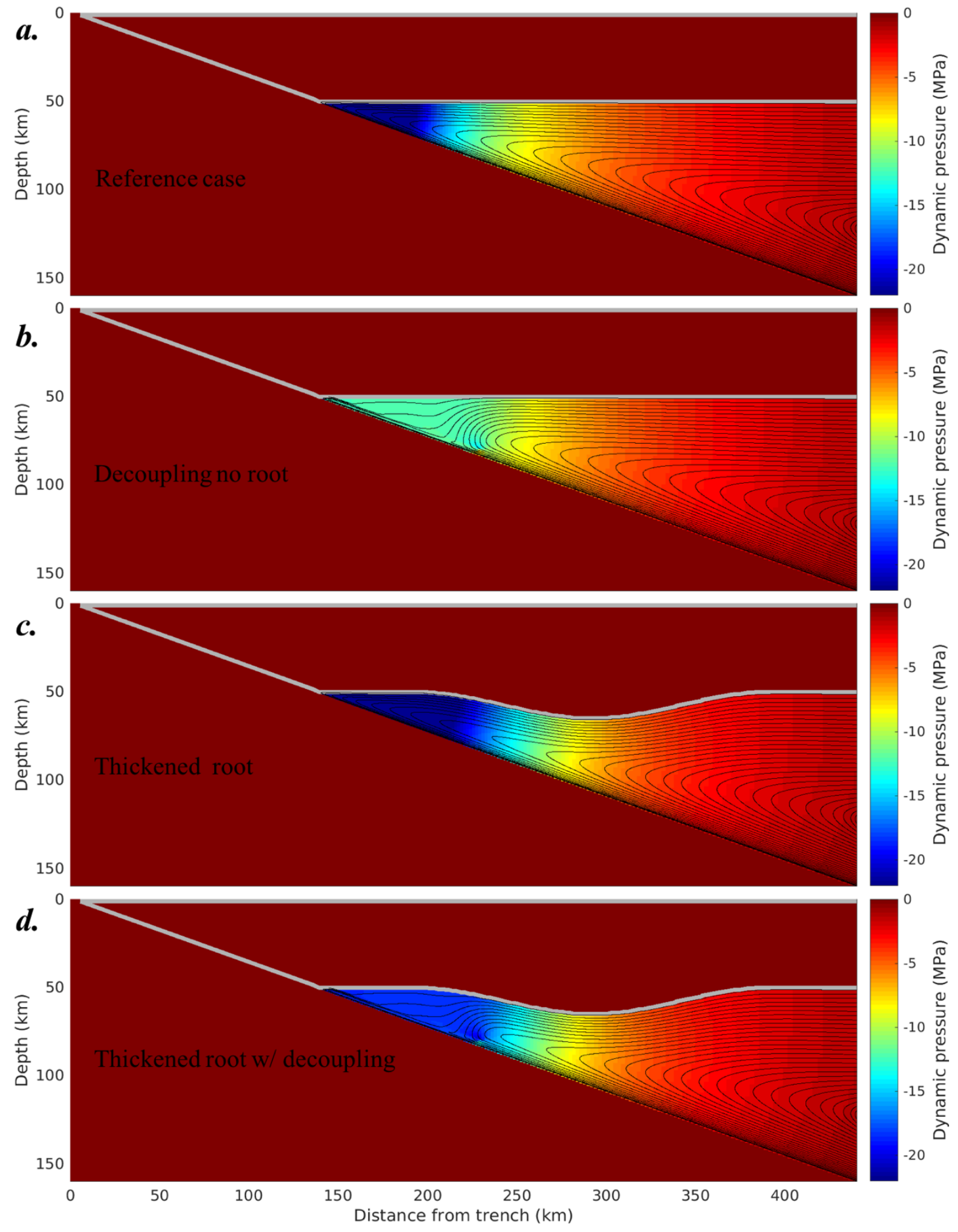

Figure 18. Plots of dynamic pressure for (a) simulation 1: reference case, (b) simulation 2: decoupling no root, (c) simulation 3: thickened root with decoupling, (d) simulation 4: thickened root with decoupling. 


\subsection{Mantle flow}

Figure 19 illustrates the pattern of flow in the mantle wedge for a variety of cases. Velocity vectors are plotted as black arrows, with their direction and length corresponding to the motion in the mantle. Colors represent the magnitude of upward velocity, and can be interrupted to represent the relative rate of decompression as material from a deeper depth is transported to a shallower region, during which the lithostatic pressure is reduced. We see that the upper plate geometry and the subducting plate motion dictate the behavior of flow in the mantle wedge. The exception being an anomaly in the upward velocity field associated with the sharp transition between decoupled and coupled slab-mantle interface, directly above the maximum depth of decoupling where the slab is at a depth of $80 \mathrm{~km}$. 


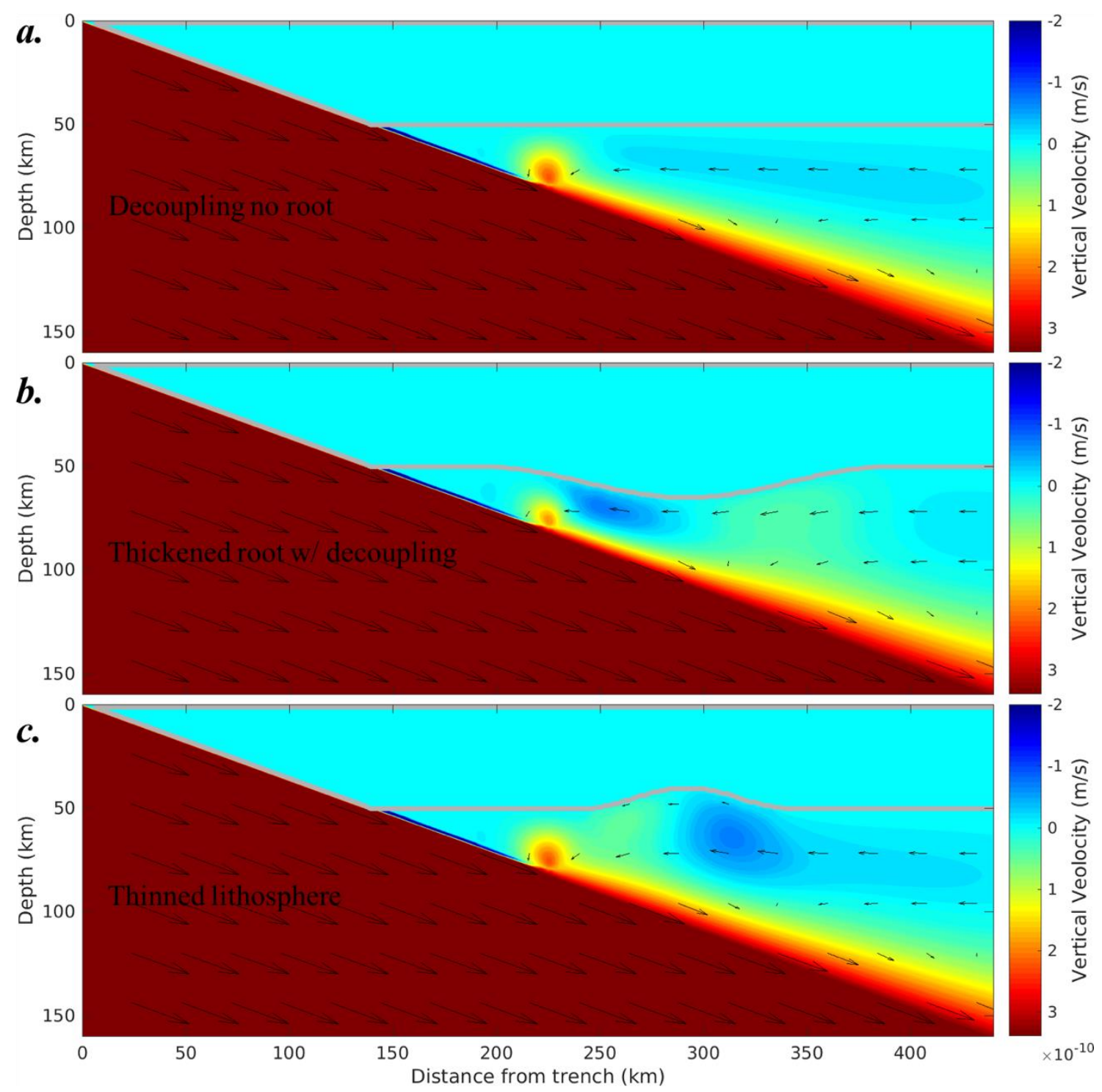

Figure 19. Plots of vertical velocity $u_{y}$ for (a) simulation 2: decoupling no root, (b) simulation 4: thickened root with decoupling, (c) simulation 6: thinned lithosphere. Velocity vectors are shown as black arrows and their length correspond to the magnitude. Positive velocity is defined as downward. 


\subsection{Melt production}

Figure 20 combines the steady state temperature, mantle wedge flow field and the rate of melt production for 4 unique cases, aimed to highlight the effects of crustal thickening and viscous decoupling. Figure 20a is the reference case where no crustal thickening nor viscous decoupling is applied. Figure 20b is identical to Figure 20a except for the addition of a thickened crustal root. Figure 20c is identical to Figure 20a with the inclusion of viscous decoupling to a maximum depth of $80 \mathrm{~km}$. Similarly, Figure $20 \mathrm{~d}$ is identical to Figure $20 \mathrm{~b}$ with the viscous decoupling added. Two more cases are show in Figure 21, where the maximum depth of decoupling was increased to $120 \mathrm{~km}$ (Figure 21a). Figure 21b is identical to Figure 20d except a thinned lithosphere (the opposite of a crustal root) is present.

The variability of melt production along the entire length of the subduction zone for all cases are shown in Figure 22, Figure 23, and Figure 24. This is accomplished by vertically integrating the melt production rate presented in Figure 20 and Figure 21. This melt production quantity represents the volume of melt generated per unit area along strike per time. Lastly, a list of simulation results with varying free parameters such as root size and decoupling extent are summarized in, along with total melt production for the arc front defined as volume of melt per arc length per time. 

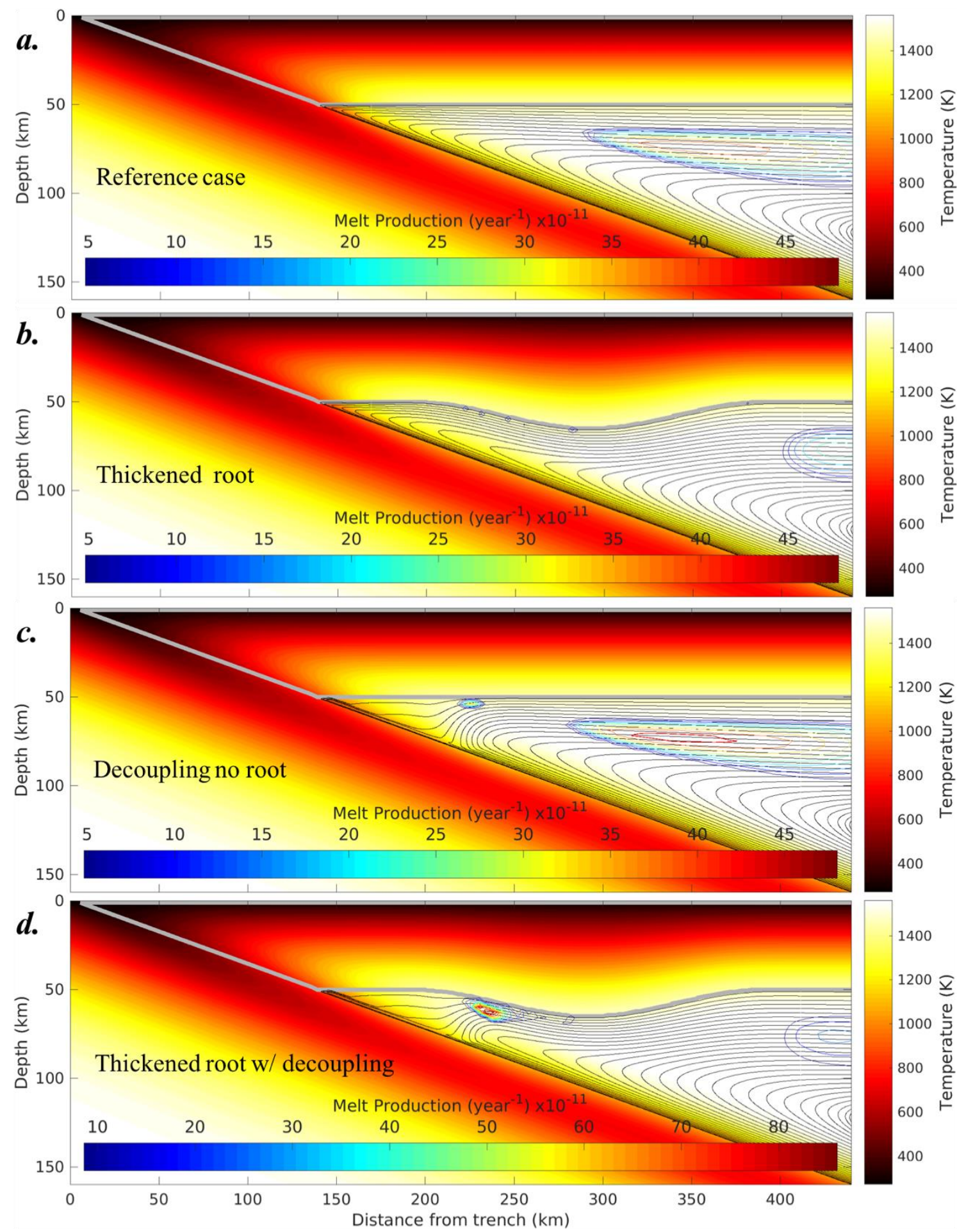

Figure 20. Results of steady-state temperature (pseudocolor), and streamlines (black curves) for corner-flow simulations 1-4 (Table 2) with a stationary over-riding plate and a subducting slab with prescribed motion. Colored 
contours represent the rate of melt production (volumetric ratio of melt per volume per time) based on Katz et al. (2003) hydrous, adiabatic melting model. (a) Reference case. (b) Identical simulation setup except for the inclusion of a thickened crustal root $(15 \mathrm{~km})$ on the over-riding plate. (c) Identical to (a) except for the addition of viscous decoupling by incorporating a low viscosity zone in the forearc slab-mantle interface to a maximum depth of $80 \mathrm{~km}$. (d) Identical to (b) except for the inclusion of viscous decoupling.

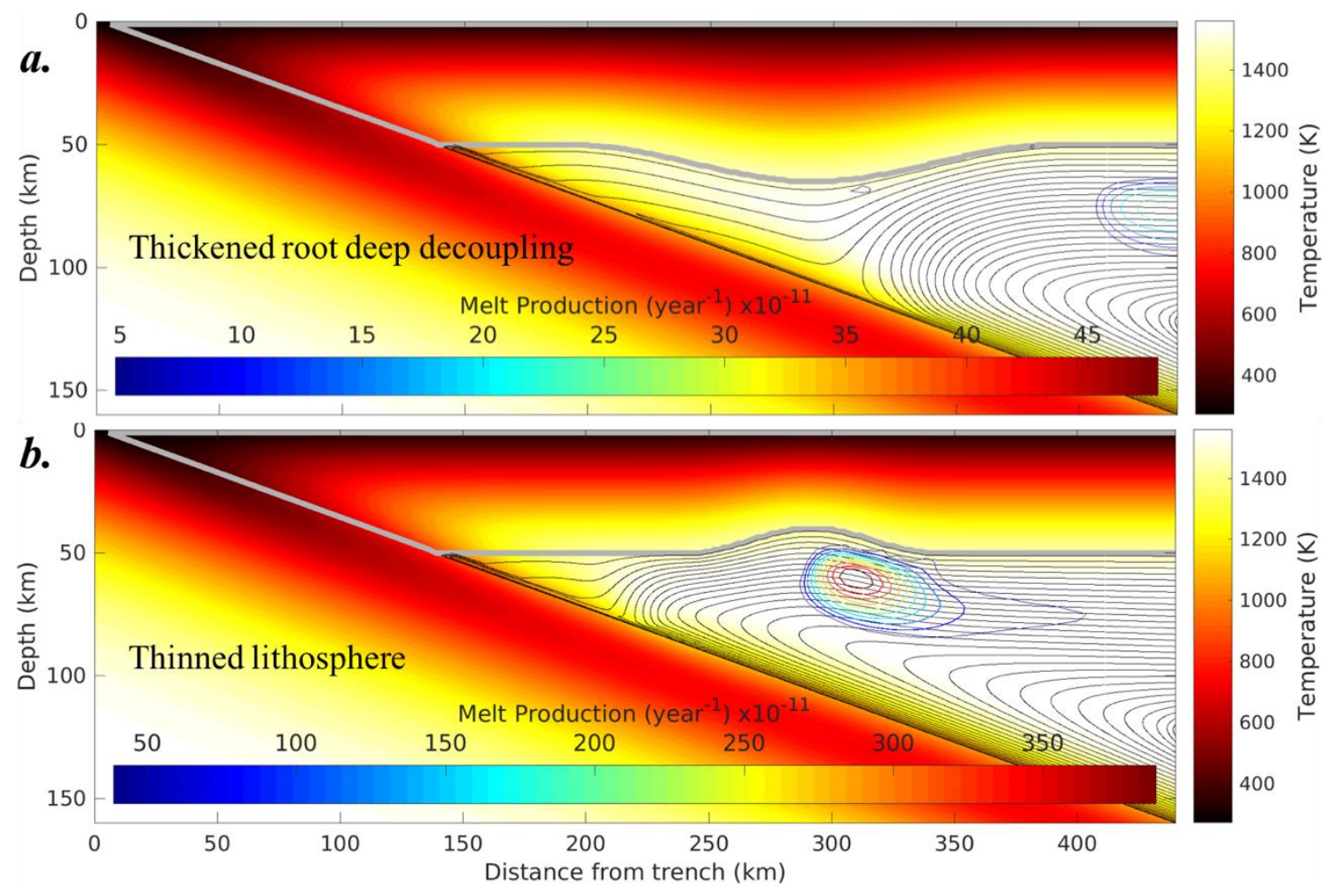

Figure 21. Results of steady-state temperature (pseudocolor), and streamlines (black curves) for corner-flow simulations 5 and 6. (a) Identical to Figure $20 \mathrm{~d}$ but deeper maximum depth of decoupling $(120 \mathrm{~km}$ ). (b) Identical to Figure $20 \mathrm{~d}$ but instead of thickened root, a thinned lithospheric cavity is present. 


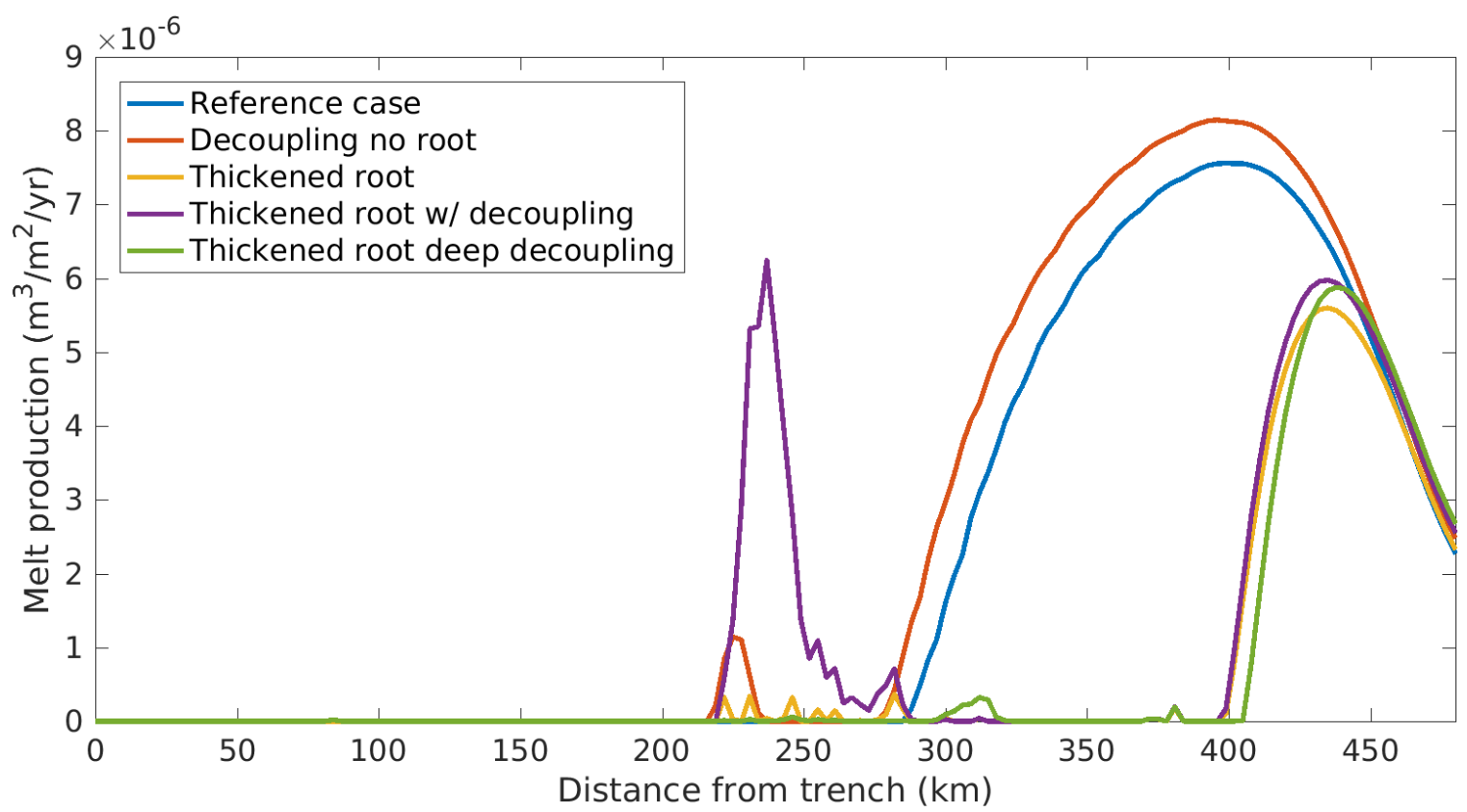

Figure 22. Summary of modeling results showing the variability of melt production defined as volume of melt per surface area per time. A comparison is made for simulations $1-5$.

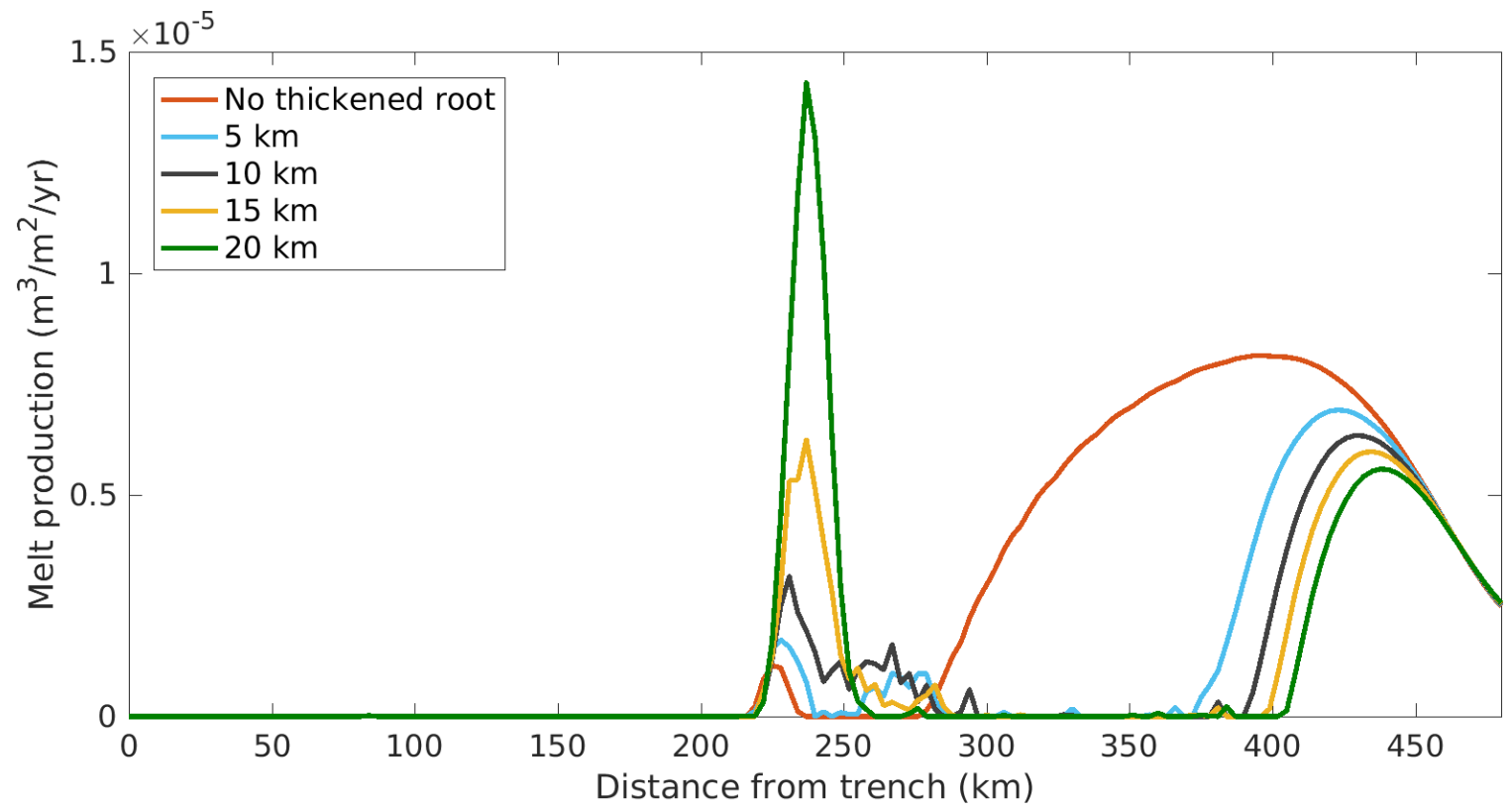

Figure 23. Summary of modeling results showing the variability of melt production as a function of changing root size. A comparison is made for simulations $2,4,7,8$, and 9 . 


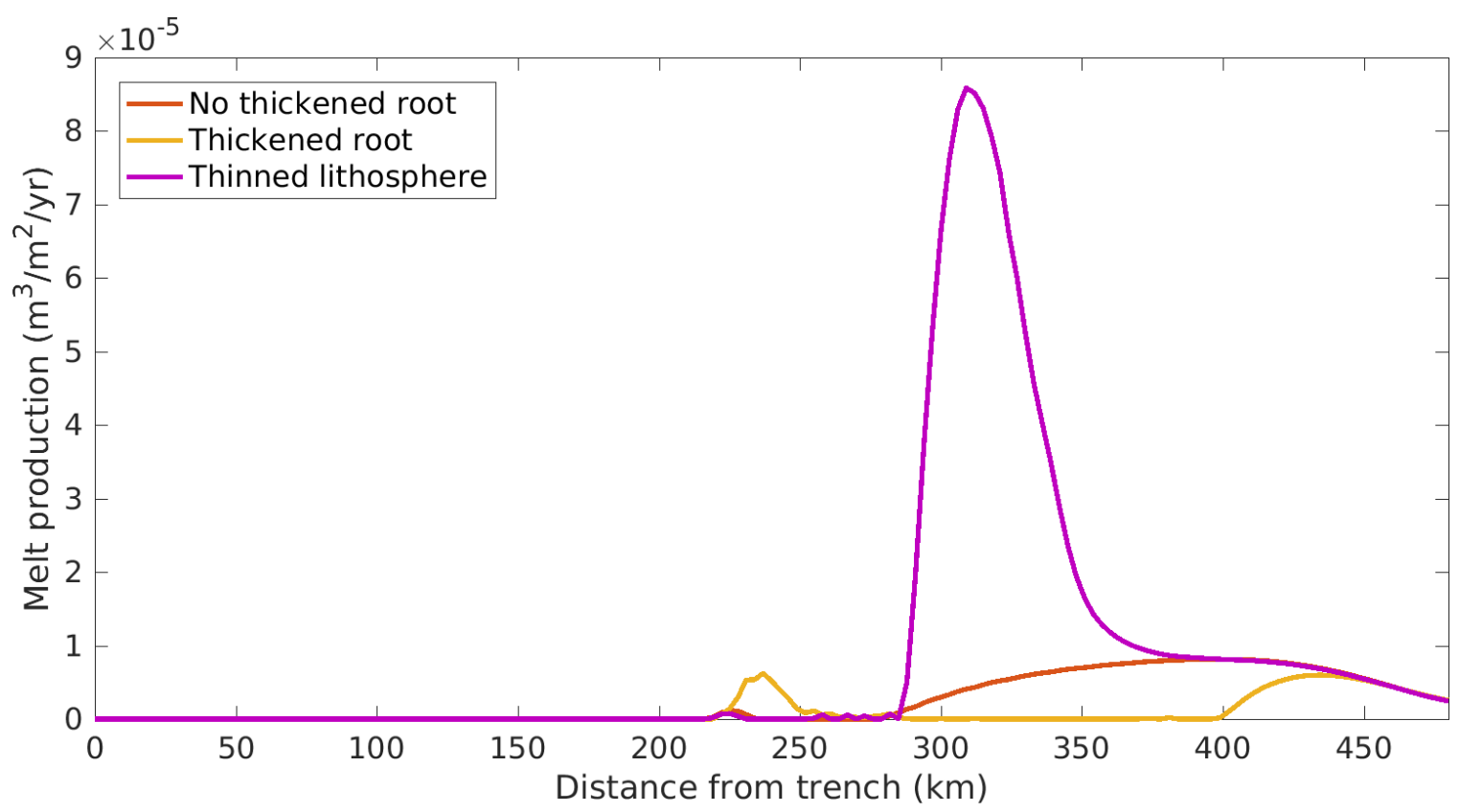

Figure 24. Summary of modeling results showing the variability of melt production as a function of changing root size. A comparison is made between simulations 2,4 , and 6 . 


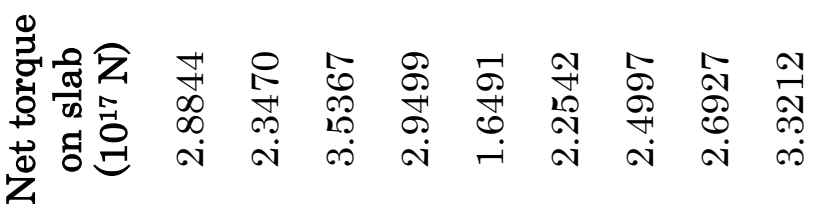

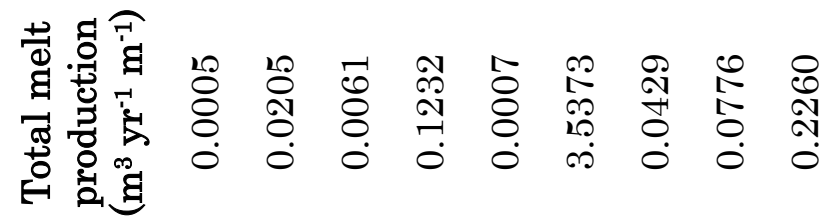

导声

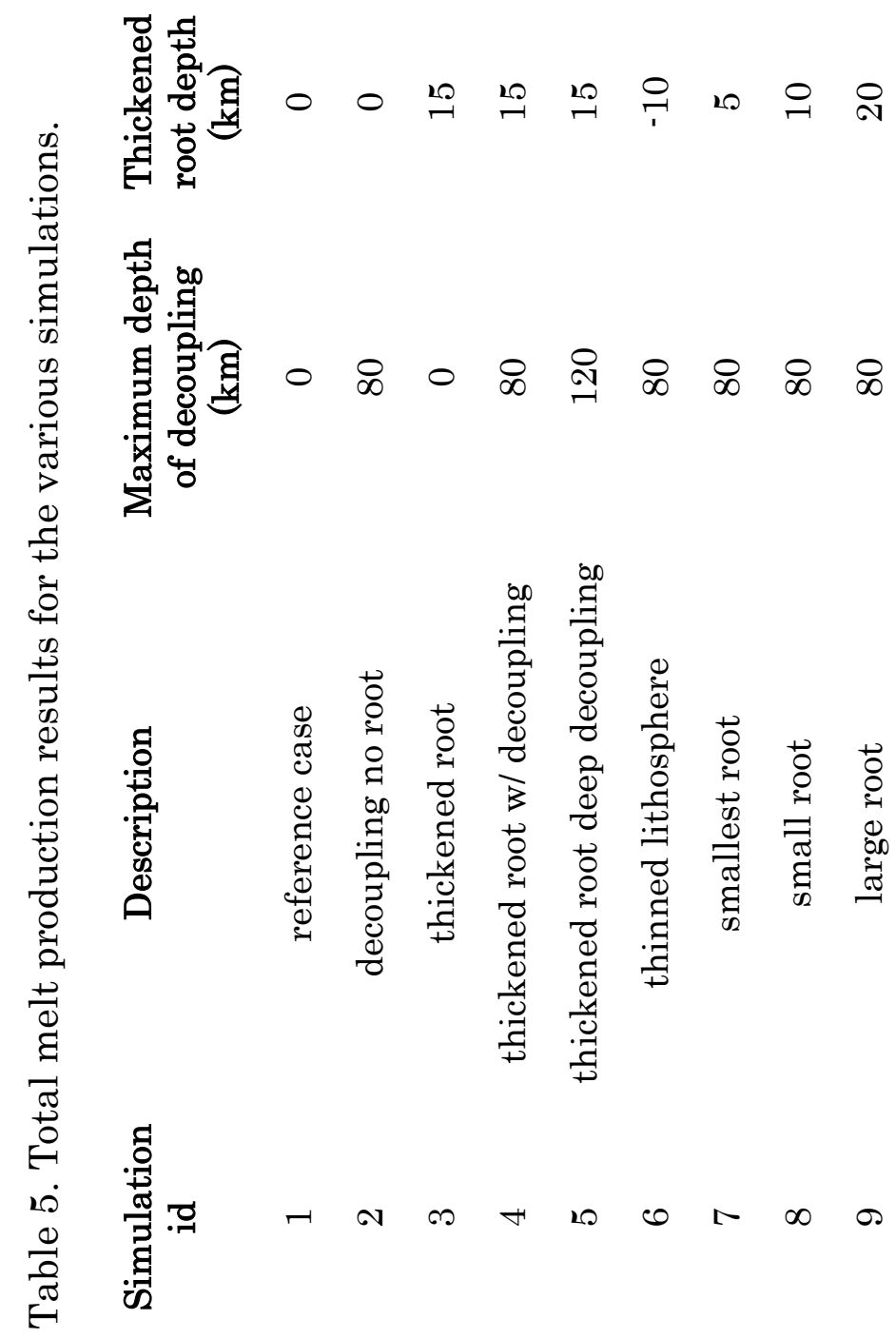




\section{DISCUSSION}

We explored the effects of crustal thickening and viscous decoupling on decompression melting in the mantle wedge using simplified 2D numerical simulations. It is important to address some of the limitations and key assumptions in our approach. First, we ignore processes that produce melt originating from the subducting slab. Second, our simulations present a steady-state solution, but real subduction zones are not in steady-state due to the continuous evolution of the subducting slab, the overriding plate, and the interaction with melt. Third, we use an isoviscous mantle rheology without temperature dependence. The cold serpentinized wedge tip may modify the viscosity structure, affecting the pattern of flow in the mantle wedge, though we do not expect the central results to be affected by this simplification. Fourth, the exact geometry of the crustal root is poorly constrained. An asymmetrical root is possible, and would alter the flow in the wedge accordingly. Fifth, the mantle wedge in our model is homogenous and equally fertile everywhere at all times. In reality, heterogeneities in water content and depletion of incompatible elements also play a role in determining melt fraction. Finally, our kinematic model is limited to calculating temperature, velocity, and pressure within the wedge; thus, we don't model the extraction

and transport of melt, nor the deformation of partially molten rock and the 
resulting two-phase flow. Any melt predicated is a result of post-process calculation, and does not interact with the simulation in any way.

\subsection{Viscous decoupling}

Viscous decoupling of the slab-mantle interface produces the clear distinction in the pattern of flow observed at the "nose" of the forearc mantle (Figure 20). The obstruction of the streamlines shown in Figure 20c is inferred to represent the stagnant forearc mantle suggested by Wada and Wang (2009). This region does not participate in the counterclockwise convective corner flow, which is responsible for keeping most of the mantle wedge uniformly hot through advection. Therefore, the colder temperatures towards the tip of the mantle wedge is a result of the conductive cooling of the subducting slab and the overriding plate. Our modeling results provide support for the inferred presence of a serpentinized mantle wedge beneath Mount St Helens (Hansen et al., 2016) and eliminates the possibility of decompression-induced mantle melt originating directly above the decoupled slab-mantle interface. Landward of the decoupled region is dominated by the corner flow regime, where viscous decoupling applies a small increase in back-arc melt generation (Figure 22). This increase can be attributed to the reduction in the radius and transit time of the convective corner flow, 
increasing the rate of decompression resulting in greater amount of melt produced.

Figure 20c and d depicts the sharp transition between the coupled and decoupled mantle as the locus of arc front melt generation for cases with no root and thickened root present. This is not coincidental and can be attributed to the following: increased upward flow velocity due to shortening of horizontal flow path in the forearc mantle wedge; and increased temperatures in the region landward of the coupled/decoupled transition when viscous decoupling is applied (Figure 25). Notice that the locus of melt generation in Figure 25b does not correspond to the largest temperature increase in Figure 25c, rather, it is just above the anomalously hot area. This is due to the associated rapid downward flow near the coupled/decoupled transition, clearly shown in Figure 19. The stagnant nose of the mantle wedge acts as an effective insulator, reducing the amount of conductive cooling exerted by the slab and upper plate, as well as reducing the radius of corner flow, which provides more favorable conditions for melt generation. It can be argued that viscous decoupling is required for arc front melting to occur. However, if the maximum depth of decoupling increases significantly to $120 \mathrm{~km}$, a much larger stagnant mantle wedge is produced (Figure 21a). This results in a very small amount of arc front melting and is similar to the case without viscous decoupling, shutting down decompression melting in the 
arc front (Figure 22). Wada and Wang (2009) suggests a common maximum depth of decoupling of $\sim 80 \mathrm{~km}$ is appropriate for all subduction zones, inferred from surface heat flow data. As a result, the much deeper $(120 \mathrm{~km})$ depth of decoupling scenario explored here may not have any real significance.

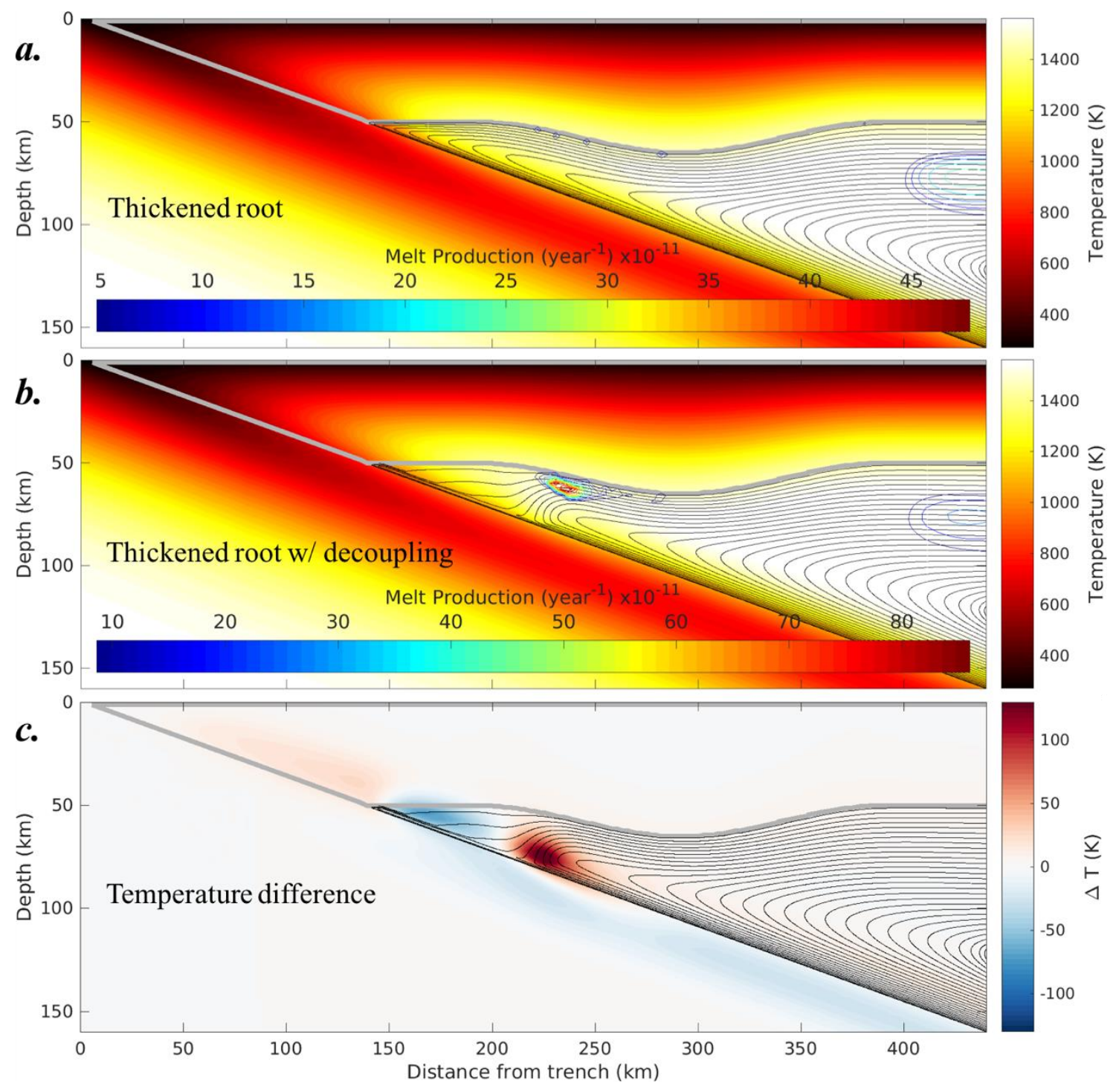

Figure 25. Differences of melt production rate between thickened root without decoupling (a) and with decoupling (b). Steady-state temperature 
differences of (b) compared to (a) is shown in (c), where regions of positive $\Delta \mathrm{T}$ indicates hotter temperatures in (b).

\subsubsection{Controls on maximum depth of decoupling}

The Maximum Depth of Decoupling (MDD) is controlled by some process that weakens the mantle rock or strengthens the slab-mantle interface layer (Wada and Wang, 2009). In our model the weaker interface layer above the MDD has a viscosity that is 4 orders of magnitude less compared to the ambient mantle, while below the MDD the viscosity contrast is absent. If the reduced viscosity of the interface is attributed to fluids resulting from slab dehydration reactions, then the MDD should vary with the thermal state of the subducting slab. However, Wada and Wang (2009) proposes that a common MDD of 70-80 km exists for most subduction zones. They attribute the MDD to the disappearance of the strength contrast between the hydrous minerals along the interface and the overlying mantle. While the strength of both the hydrous minerals and mantle olivine depend on temperature and pressure, laboratory results show that decrease in their strength with depth due to increasing temperature is more rapid for wet olivine than for antigorite, resulting in a decrease in strength contrast (Hilairet et al., 2007).

The strongest evidence supporting the claim of a common depth of decoupling for subduction zones came from surface heat flow measurements, 
which has been shown to exhibit similar patterns across subduction zones with varying slab thermal states. Based on the observation that most arcs are situated where the slab is $\sim 100 \mathrm{~km}$ deep; Wada and Wang (2009) contribute the observed sharp transition from low surface heat flow of the forearc to the high surface heat flow of the arc and backarc to the effects of viscous decoupling just updip of the arc front, resulting in a stagnant forearc mantle and a circulating mantle immediately downdip. The assumption here is that surface heat flow measurements from wells and boreholes indicate temperatures in the upper mantle. The validity of this assumption can be questioned because a number of other factors also influence heat flow of the uppermost crust. Lithosphere thickness, residual magmatic heat, hydrothermal activity, thermal advection of groundwater due to precipitation are all capable of altering surface heat flow observations. It is possible that the apparent surface heat flow observations are the result of these shallow, lithospheric processes rather than dynamics of the mantle due to the occurrence of viscous decoupling.

\subsection{Lithospheric thickening}

Presence of the thickened lower crustal root causes deflection in the regular, wedge like mantle flow field. As a hypothetical parcel of rock moves along the curvature of this bulge, decompression melting occurs in a 
relatively small region where the upward flow velocity is high (Figure $20 \mathrm{~d}$ and Figure 19b). The magnitude of upward flow velocity dictates the rate of decompression as material from a deeper depth is transported to a shallower region, during which the lithostatic pressure is reduced. Therefore, cases with thickened root produce more arc front melting than cases without, due to the localized upstream flow providing favorable conditions for decompression melting. In addition, the calculated spatial distribution of melt generation is limited, contrasting the broad melting behavior seen for cases without a thickened root (Figure 20). In the absence of possible melt focusing mechanisms during ascent, the correlation between lower lithospheric structure and the locus of melt production provide an explanation for the unresolved problem that partial melting of the upper mantle is thought to occur over a broad region in the mantle wedge, while the observed volcanic arc front is much narrower (Syracuse and Abers, 2006; England and Katz 2010). Furthermore, the depth of the thickened root is directly related to the productivity of the arc front (Figure 23), as a deeper root induces more rapid upstream flow trenchward of the thickened region, enhancing decompression melting of the mantle.

All cases with thickened root regardless of size show diffused melt generation $\sim 100 \mathrm{~km}$ landward from the arc front (Figure 23). We interpret this broader region of melting, far away from the trench, as the mantle source 
of back-arc magmatism, resulting from the boundary conditions. The motion of the subducting slab drives flow in the wedge and includes a downward component. As material located directly above the slab is transported deeper into the mantle, there is an equal but opposite upward component associated with the corner flow, bringing material to a shallower depth along the inflow below the upper plate. The magnitude of this back-arc melting is sensitive to the size of the convection cell, or the width of the asthenospheric mantle in the subduction model. Our modeled mantle is limited to $\sim 400 \mathrm{~km}$ in the horizontal direction, for the purpose of reducing simulation duration to a reasonable amount of time. However, a much larger corner flow radius may be needed to accurately represent the Cascadia subduction system if the distance from subduction trench to the Yellowstone Hotspot is used to represent the width of the convection cell. The separation between arc front and back-arc melt generation is enabled by the compressive downward flow landward of the thickened root, which modulates the otherwise gradual upward inflow (Figure 20).

\subsubsection{Torque exerted on slab}

Thickening of the overriding plate increases the dynamic pressure in the mantle wedge (Figure 18). Dynamic pressure in the mantle wedge is one of the controls of slab dip angle. Changes in dynamic pressure and the resulting suction force can cause shallowing or steepening of the subduction 
angle, potentially affecting flow pattern and melt generation in the mantle wedge (Rodriguez-Gonzalez et al., 2014). The torque exerted on the slab due to dynamic pressure increases with the progressive thickening of the overriding plate 0 , consistent with the analytical corner flow solutions of Stevenson and Turner (1977). In particular, a thickened root with a depth that is $20 \%$ of the overriding plate thickness increases the torque on the slab by $\sim 15 \%$. This increase significantly alters the torque balance, favoring shallowing of the subducting slab as the crust thickens.

\subsubsection{Lithosphere-asthenosphere boundary}

The lithosphere-asthenosphere boundary (LAB) represents a rheological difference between layers in the Earth's interior. It is a mechanical boundary separating the cooler, overriding mantle lithosphere and the warmer, ductile mantle asthenosphere. The mantle lithosphere and asthenosphere are chemically similar, but as temperatures inside the Earth increases with increasing depth, shallow mantle rocks transition from brittle lithospheric mantle to the underlying ductile asthenosphere that's potentially melt bearing. The increase in temperature with increasing depth is known as the geothermal gradient and the LAB marks the change from purely conductive heat transport of the lithosphere to the convective, flowing asthenosphere (Sleep, 2005). This rheological difference in mantle rocks is 
due to the power-law scaling of its viscosity on temperature. Small increases in temperature may induce a profound contribution on lowering the viscosity of the upper mantle, enabling rocks to "flow" over geological time.

Inferences on the depth of the LAB are derived from seismological constraints based on wave speeds. Within the upper mantle the LAB is indicated by the high velocity layer above the asthenospheric low velocity zone. Determination of the LAB depth is complicated by the numerous mechanisms that exist for the velocity decrease from lithosphere to asthenosphere: temperature, volatile content, partial melt, composition, grain size, and anisotropy. A number of studies focused in the western United States have produced varying lithosphere thickness maps (e.g. Levander and Miller, 2012; Hopper et al., 2013; Till et al., 2013; Gao and Shen, 2014). Because spatial resolution of the resulting maps depend directly on the resolution of seismic stations, variances of the LAB across the Cascades arc is not yet available. In order to reconcile the uncertainty associated with lithosphere thickness across the arc, we explored three scenarios: 1. A lithosphere of constant thickness; 2. A thickened root directly beneath the arc front; 3. Thinned lithosphere beneath the arc due to interaction with melt and thermal erosion. 


\subsection{Arc front migration}

There is evidence supporting landward migration of the Cascades arc front since $\sim 45 \mathrm{Ma}$, most notably the ancestral Cascades located west of the modern high Cascades (du Bray and John, 2011). A traditional interpretation is that the slap dip angle is inversely correlated with the distance from arc front to subduction trench (Dickinson and Snyder, 1978). Therefore, landward migration of the arc front would suggest shallowing of the subducting slab with time. Since oceanic plates cool as they move away from spreading centers with increasing age and foundering of the subducting slab is the result of this negative thermal buoyancy; one would associate a shallowing slab with reduction of its age at the trench. The younging of the Cascadia subduction system and the associated evolution in wedge geometry may explain the observed landward shift of arc volcanism.

Slab-induced changes to the subduction zone has been correlated to the slab thermal parameter, $\varphi$, a product of the age and descent rate of the subducting slab (McKenzie, 1969). Generally, the lower the $\varphi$ value, the warmer the subducting slab is at a given depth. With an average age of $8 \mathrm{Ma}$ at the trench (Wilson 1988), a convergence rate of $36 \mathrm{~mm} / \mathrm{yr}$ (Gripp and Gordon, 2002) and a dip angle of $18^{\circ}$ (Hayes et al., 2012), the Juan de Fuca plate has the lowest $\varphi$ value among major subducting plates globally. As a result, the peak of slab dehydration reactions, indicated by the basalt to 
eclogite transformation in the subducting crust occurs at a relatively shallow depth of $\sim 45 \mathrm{~km}$, inferred from scattered teleseismic body waves (Bostock et al., 2002). If subduction zone kinematics are assumed constant, a younging subducting slab would favor dehydration reactions at shallower depths, shifting melt generation and volcanism trenchward. Our modeled mantle is homogenous in terms of water content and does not incorporate dehydration processes, but the thermal state of the relatively warm subducting slab reduces the amount of conductive cooling. This effect is greatest at the forearc mantle, resulting in warmer temperatures and potentially enabling melt generation closer to the trench. Furthermore, if hydrous flux melting is accounted for in our model, we expect the locus of fluid-induced melt generation to overlie the location of peak dehydration reactions in the slab, where the surface of the slab is at a depth of $\sim 45 \mathrm{~km}$, near the nose of the mantle wedge.

Alternatively, changes in the kinematics of the overriding plate have also been proposed to drive arc front migration. In this case, crustal block rotation is used to explain the apparent landward migration of the Cascades arc front (Wells and McCaffrey, 2013). Modern GPS measurements of plate motion extrapolated back in time paired with geologic mapping have been used to argue that rigid crustal blocks on the Western margin of North America have experienced clockwise rotation about a fixed pole over the last 
$\sim 40$ Myr. The dextral shear from the oblique convergence of the subducting Juan de Fuca plate causes the crustal blocks to rotate and decouple from the fixed underlaying mantle, causing apparent migration of the Cascades arc.

We explored Cascades arc front migration in the context of changing lithospheric thickness. Our results do not support the conclusion of Karlstrom et al. (2014) that thickening of the upper plate causes arc front migration away from the trench. As mentioned previously, a crustal root protruding into the asthenosphere deflects the mantle flow field. Decompression-induced melting is focused where the upstream is most rapid, trenchward of the thickened root associated with the arc front. Therefore, the evolution of a subduction system with a thickened crustal root present in the mantle wedge is characterized by a progressive trenchward growth of the root and the associated migration of the arc front in the same direction. This conclusion however, is not consistent with thickened crust beneath the Cascades arc (Figure 5) and the observed landward migration of the arc front (du Bray and John, 2011). The location of the arc front is inferred based on the locus of melt production, assuming vertical transport. Lateral transport of melt within the wedge maybe important, though the dynamic pressure gradient decreases towards the tip of the mantle wedge, which further amplifies the trenchward growth of the crustal root. 


\subsubsection{Landward migration and lithospheric thinning}

To reconcile the inconsistency between model predictions and observations, let's consider the possibility of a thickened crustal root that is underlain by a thinned or potentially absent mantle lithosphere. In our model, an important assumption in the structure of the overriding plate is that the lithosphere has a constant thickness. As a result, localized thickening of the crust is mirrored by the depth of the LAB, which affects flow in the simulated asthenospheric mantle. Lithospheric thinning, the reduction of mantle lithosphere thickness beneath arcs due to localized thermal erosion has been proposed by England and Katz (2010) to explain the focusing of mantle melt. This idea is further tested by Perrin et al. (2016), where primitive arc lava equilibration temperatures suggest that thermal erosion of the lithosphere below the arcs is required. We explore the effect of lithospheric thinning by modifying the structure of the overriding plate, so that directly beneath the arc, the overriding plate is $10 \mathrm{~km}$ shallower than everywhere else (Figure 21b). The resulting melt pattern experiences a landward shift due to the upstream flow occurring landward of the thinned region, as well as a large increase in arc front melt productivity (Figure 24). The increase of melt generation can be attributed to the presence of the large region of relative high upward flow velocity (Figure 19c) and the shallowing of LAB, effectively reducing lithostatic pressure, promoting decompression 
melting. In this case thickening of the crustal root is accompanied by thinning of the mantle lithosphere, such that the resulting LAB is shallowest beneath the Cascades arc. Mantle melt produced landward of the arc front continues to thermally erode the lithosphere during ascent, and migration of the arc front away from the trench is achieved.

The inferred thinning of the mantle lithosphere beneath the Cascades arc is consistent with structural features indicating extensional tectonics resulting from the uplift due to isostatic compensation. As denser mantle lithosphere is converted to lighter asthenosphere due to thermal erosion, surface topography is expected to increase. Using our crustal model as a crude approximation and an assumed mantle lithosphere whose density is $100 \mathrm{~kg}$ greater than that of the mantle asthenosphere, a $10 \mathrm{~km}$ thinning of the mantle lithosphere results in $\sim 300 \mathrm{~m}$ of surface uplift. The proposed model of gradual thinning of the mantle lithosphere is consistent with the progressive uplift and landward migration of the Cascades Range.

For most subduction zones globally, volcanism is scarce trenchward of the arc front. This observation is in conflict with the model results showing a high degree of decompression melt trenchward of the arc root. There are several factors and assumptions in the model which could cause this. First and foremost, the bulge-like lithosphere structure with the thickened root beneath the arc is questionable. As mentioned previously, the depth of the 
LAB is poorly constrained and we propose a scenario of lithospheric thinning to explain the landward migration of the Cascades. In addition, the extent of viscous decoupling is debatable. The common maximum depth of decoupling of $80 \mathrm{~km}$ (Wada and Wang, 2009) is used, which puts decoupling just upstream of the thickened lithosphere. Deepening of the decoupling extent with time may drive landward melt migration. Lastly, the kinematics of the subducting slab in our model is prescribed and we've shown through torque balance that a thickening overriding plate promotes shallowing of the subducting slab. A dynamic, shallowing slab would push hot isotherms in the mantle wedge away from trench, causing landward migration of the arc front. 

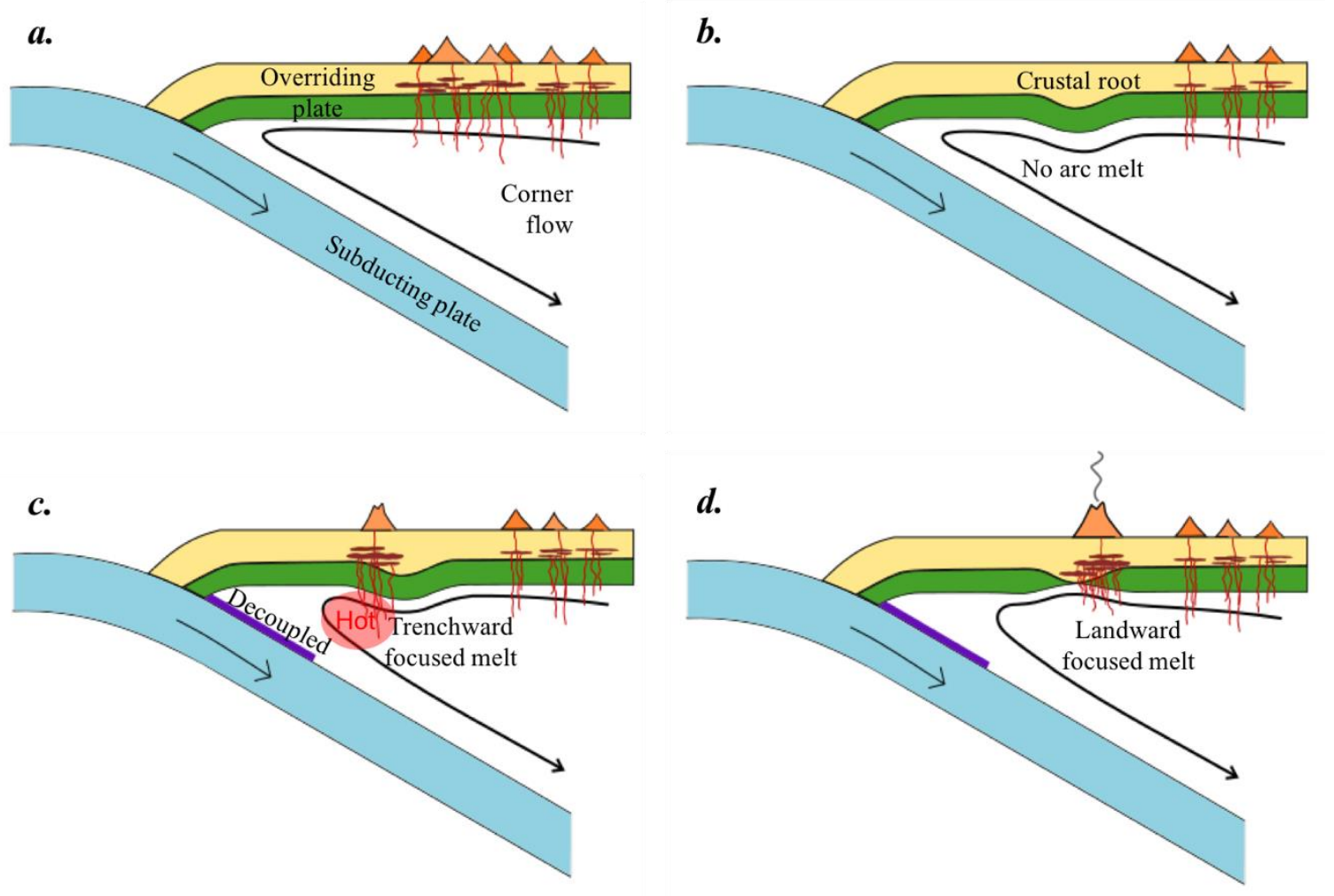

Figure 26: Conceptual model illustrating the changes to mantle melt generation as a result of varying simulation parameters. The over-riding plate consist of the crust (yellow) and the underlying mantle lithosphere (green). Purple stripe represents decoupling layer. (a) Reference case with no decoupling or crustal root with a broad region of melt generation. (b) Presence of a crustal root inhibits flow and produces no arc front melting. (c) Decoupling reduces the radius of corner flow and enables arc front melt production trenchward of the thickened lithosphere. (d) Lithospheric thinning beneath the arc produces greater amounts of mantle melt at shallower depths and shifts the locus of arc front melting landward. 


\section{CONCLUSIONS}

By modifying lithospheric topography and incorporating viscous decoupling, we make the following conclusions.

1. A thickened crustal root modulates the mantle flow field, causing material to move around it. Decompression melting does not occur landward of the root due to the deflected, downward flow. The locus of melt generation is trenchward of the thickened region, where upward flow is relatively rapid. This results in a gap between the locations of focused arc front and diffused back-arc melt generation. The size of the thickened root is proportional to melt productivity.

2. Lithospheric thinning promotes high rates of melt production landward of the arc. Shallowing of the LAB beneath the arc explains the observed landward migration of the Cascades arc front assuming crustal thickening and lithospheric thinning are occurring in concert, following the idea of thermal erosion at the base of the lithosphere due to ascending mantle-derived melt. In this case the locus of melt generation is landward of the thinned lithosphere, and the shifting of the melt locus away from the trench may cause subsequent erosion of the lithosphere further still from the trench, a feedback process favoring landward migration of the arc front. 
3. Constant lithosphere thickness promotes broad, diffused mantle melt while varying LAB concentrates melt locus, favoring a narrow, well defined arc front.

4. Thickened crustal root increases the torque exerted on the slab due to suction, favoring slab shallowing; viscous decoupling has the opposite effect.

5. Viscous decoupling of the slab-mantle interface produces a colder, stagnant "nose" in the mantle wedge that is melt free while at the same time enables arc front melt generation. This is achieved through reduction of the radius of corner flow, minimizing the conductive cooling of the slab/overriding plate, leading to increases in mantle temperature immediately landward of the transition between decoupled and coupled mantle. 


\section{REFERENCES}

Abers, G.A., van Keken, P.E., Kneller, E.A., Ferris, A. and Stachnik, J.C., 2006. The thermal structure of subduction zones constrained by seismic imaging: Implications for slab dehydration and wedge flow. Earth and Planetary Science Letters, 241(3), p. 387-397.

Amestoy, P.R., Duff, I.S., L'Excellent, J.Y. and Koster, J., 2001. A fully asynchronous multifrontal solver using distributed dynamic scheduling. SIAM Journal on Matrix Analysis and Applications, 23(1), pp.15-41.

Amestoy, P.R., Guermouche, A., L'Excellent, J.Y. and Pralet, S., 2006. Hybrid scheduling for the parallel solution of linear systems. Parallel computing, 32(2), pp.136-156.

Balay, S., Abhyankar, S., Adams, M.F., Brown, J., Brune, P., Buschelman, K., Eijkhout, V., Gropp, W., Kaushik, D., Knepley, M., McInnes, L.C., Rupp, K., Smith, B. and Zhang, H., 2014. PETSc Users Manual. Technical report.

Bird, P., 2003. An updated digital model of plate boundaries. Geochemistry, Geophysics, Geosystems, 4(3).

Blakely, R.J., Brocher, T.M. and Wells, R.E., 2005. Subduction-zone magnetic anomalies and implications for hydrated forearc mantle. Geology, 33(6), p. $445-448$.

Blankenbach, B., Busse, F., Christensen, U., Cserepes, L., Gunkel, D., Hansen, U., Harder, H., Jarvis, G., Koch, M., Marquart, G. and Moore, D., 1989. A benchmark comparison for mantle convection codes. Geophysical Journal International, 98(1), pp.23-38.

Bostock, M.G., Hyndman, R.D., Rondenay, S. and Peacock, S.M., 2002. An inverted continental Moho and serpentinization of the forearc mantle. Nature, 417(6888), p. 536-538.

Brocher, T.M., Parsons, T., Tréhu, A.M., Snelson, C.M. and Fisher, M.A., 2003. Seismic evidence for widespread serpentinized forearc upper mantle along the Cascadia margin. Geology, 31(3), p. 267-270.

Chin, E.J., Lee, C.T.A., Luffi, P. and Tice, M., 2012. Deep lithospheric thickening and refertilization beneath continental arcs: case study of the $\mathrm{P}, \mathrm{T}$ and compositional evolution of peridotite xenoliths from the Sierra Nevada, California. Journal of Petrology, 53(3), p. 477-511.

Conder, J.A., Wiens, D.A. and Morris, J., 2002. On the decompression melting 
structure at volcanic arcs and back-arc spreading centers. Geophysical Research Letters, 29(15).

Currie, C.A. and Hyndman, R.D., 2006. The thermal structure of subduction zone back arcs. Journal of Geophysical Research: Solid Earth, 111(B8), doi:10.1029/2005JB004024.

Davies, J.H. and Stevenson, D.J., 1992. Physical model of source region of subduction zone volcanics. Journal of Geophysical Research: Solid Earth, 97(B2), p. 2037-2070.

Dickinson, W.R. and Snyder, W.S., 1978. Plate tectonics of the Laramide orogeny. Geological Society of America Memoirs, 151, pp.355-366.

du Bray, E.A. and John, D.A., 2011. Petrologic, tectonic, and metallogenic evolution of the Ancestral Cascades magmatic arc, Washington, Oregon, and northern California. Geosphere, 7(5), pp.1102-1133.

Elkins-Tanton, L. T., Grove, T. L. \& Donnelly-Nolan, J., 2001. Hot shallow melting under the Cascades volcanic arc. Geology 29, 631-634.

England, P., Engdahl, R. and Thatcher, W., 2004. Systematic variation in the depths of slabs beneath arc volcanoes. Geophysical Journal International, 156(2), pp.377-408.

England, P.C. and Katz, R.F., 2010. Melting above the anhydrous solidus controls the location of volcanic arcs. Nature, 467(7316), p. 700-703.

England, P. and Wilkins, C., 2004. A simple analytical approximation to the temperature structure in subduction zones. Geophysical Journal International, 159(3), pp.1138-1154.

Furukawa, Y., 1993. Depth of the decoupling plate interface and thermal structure under arcs. Journal of Geophysical Research: Solid Earth, 98(B11), p. 20005-20013.

Gerya, T., 2009. Introduction to numerical geodynamic modelling. Cambridge University Press.

Gerya, T.V. and Yuen, D.A., 2003. Characteristics-based marker-in-cell method with conservative finite-differences schemes for modeling geological flows with strongly variable transport properties. Physics of the Earth and Planetary Interiors, 140(4), pp.293-318.

Gerya, T.V. and Yuen, D.A., 2007. Robust characteristics method for modelling multiphase visco-elasto-plastic thermo-mechanical problems. Physics of the Earth and Planetary Interiors, 163(1), p. 83-105.

Gripp, A.E. and Gordon, R.G., 2002. Young tracks of hotspots and current plate velocities. Geophysical Journal International, 150(2), p. 321-361. 
Hansen, S.M., Schmandt, B., Levander, A., Kiser, E., Vidale, J.E., Abers, G.A. and Creager, K.C., 2016. Seismic evidence for a cold serpentinized mantle wedge beneath Mount St Helens. Nature Communications, 7.

Hasegawa, A., Horiuchi, S. and Umino, N., 1994. Seismic structure of the northeastern Japan convergent margin: A synthesis. Journal of Geophysical Research: Solid Earth, 99(B11), p. 22295-22311.

Hayes, G.P., Wald, D.J. and Johnson, R.L., 2012. Slab1. 0: A threedimensional model of global subduction zone geometries. Journal of Geophysical Research: Solid Earth, 117(B1), doi:10.1029/2011JB008524.

Hildreth, W., 2007. Quaternary magmatism in the Cascades-geologic perspectives (No. 1744). Geological Survey (US).

Hirth, G. and Kohlstedt, D., 2003. Rheology of the upper mantle and the mantle wedge: A view from the experimentalists. Inside the subduction Factory, pp.83-105.

Hofmann, A.W., 1997. Mantle geochemistry: the message from oceanic volcanism. Nature, 385(6613), p. 219-229.

Hopper, E., Ford, H.A., Fischer, K.M., Lekic, V. and Fouch, M.J., 2014. The lithosphere-asthenosphere boundary and the tectonic and magmatic history of the northwestern United States. Earth and Planetary Science Letters, 402, p. 69-81.

Hyndman, R.D. and Peacock, S.M., 2003. Serpentinization of the forearc mantle. Earth and Planetary Science Letters, 212(3), p. 417-432.

Iserles, A., 2009. A first course in the numerical analysis of differential equations (No. 44). Cambridge University Press.

John, D.A., du Bray, E.A., Blakely, R.J., Fleck, R.J., Vikre, P.G., Box, S.E. and Moring, B.C., 2012. Miocene magmatism in the Bodie Hills volcanic field, California and Nevada: A long-lived eruptive center in the southern segment of the ancestral Cascades arc. Geosphere, 8(1), pp.44-97.

Karlstrom, L., Lee, C.T. and Manga, M., 2014. The role of magmatically driven lithospheric thickening on arc front migration. Geochemistry, Geophysics, Geosystems, 15(6), p. 2655-2675.

Katz, R.F., Spiegelman, M. and Langmuir, C.H., 2003. A new parameterization of hydrous mantle melting. Geochemistry, Geophysics, Geosystems, 4(9).

Kay, S.M., Godoy, E. and Kurtz, A., 2005. Episodic arc migration, crustal thickening, subduction erosion, and magmatism in the south-central Andes. Geological Society of America Bulletin, 117(1-2), p. 67-88. 
Kelley, K.A., Plank, T., Newman, S., Stolper, E.M., Grove, T.L., Parman, S. and Hauri, E.H., 2010. Mantle melting as a function of water content beneath the Mariana Arc. Journal of Petrology, 51(8), pp.1711-1738.

Levander, A. and Miller, M.S., 2012. Evolutionary aspects of lithosphere discontinuity structure in the western US. Geochemistry, Geophysics, Geosystems, 13(7).

Lallemand, S., 1999. La Subduction Oceanique. Newark: Gordon and Breach Publishers, p. 6.

Langmuir, C.H., Bezos, A., Escrig, S. and Parman, S.W., 2006. Chemical systematics and hydrous melting of the mantle in back-arc basins. BackArc Spreading Systems: Geological, Biological, Chemical, and Physical Interactions, p. 87-146.

Lee, C.T.A., Morton, D.M., Kistler, R.W. and Baird, A.K., 2007. Petrology and tectonics of Phanerozoic continent formation: from island arcs to accretion and continental arc magmatism. Earth and Planetary Science Letters, 263(3), pp.370-387.

Lee, C.T.A., Luffi, P., Plank, T., Dalton, H. and Leeman, W.P., 2009. Constraints on the depths and temperatures of basaltic magma generation on Earth and other terrestrial planets using new thermobarometers for mafic magmas. Earth and Planetary Science Letters, 279(1), p. 20-33.

Leng, W. and Zhong, S., 2011. Implementation and application of adaptive mesh refinement for thermochemical mantle convection studies. Geochemistry, Geophysics, Geosystems, 12(4).

McKenzie, D.P., 1969. Speculations on the consequences and causes of plate motions. Geophysical Journal International, 18(1), pp.1-32.

Monger, J. W. H., and R. A. Price, 2002, The Canadian Cordillera: Geology and tectonic evolution, Canadian Society of Geophysicists Recorder, 27, p. 17 - 36 .

Miura, S., Kodaira, S., Nakanishi, A., Tsuru, T., Takahashi, N., Hirata, N. and Kaneda, Y., 2003. Structural characteristics controlling the seismicity crustal structure of southern Japan Trench fore-arc region, revealed by ocean bottom seismographic data. Tectonophysics, 363(1), p. 79-102.

Nakajima, J., Matsuzawa, T., Hasegawa, A. and Zhao, D., 2001. Threedimensional structure of $\mathrm{Vp}, \mathrm{Vs}$, and $\mathrm{Vp} / \mathrm{Vs}$ beneath northeastern Japan: Implications for arc magmatism and fluids. Journal of Geophysical Research: Solid Earth, 106(B10), p. 21843-21857. 
O'Driscoll, L.J., Humphreys, E.D. and Saucier, F., 2009. Subduction adjacent to deep continental roots: Enhanced negative pressure in the mantle wedge, mountain building and continental motion. Earth and Planetary Science Letters, 280(1), pp.61-70.

Peacock, S.M. and Hyndman, R.D., 1999. Hydrous minerals in the mantle wedge and the maximum depth of subduction thrust earthquakes. Geophysical Research Letters, 26(16), p. 2517-2520.

Perrin, A., Goes, S., Prytulak, J., Davies, D.R., Wilson, C. and Kramer, S., 2016. Reconciling mantle wedge thermal structure with arc lava thermobarometric determinations in oceanic subduction zones. Geochemistry, Geophysics, Geosystems, 17(10), pp.4105-4127.

Plank, T. and Langmuir, C.H., 1988. An evaluation of the global variations in the major element chemistry of arc basalts. Earth and Planetary Science Letters, 90(4), pp.349-370.

Ramachandran, K., Dosso, S.E., Spence, G.D., Hyndman, R.D. and Brocher, T.M., 2005. Forearc structure beneath southwestern British Columbia: A three-dimensional tomographic velocity model. Journal of Geophysical Research: Solid Earth, 110(B2), doi:10.1029/2004JB003258.

Rodríguez-González, J., Billen, M.I. and Negredo, A.M., 2014. Non-steadystate subduction and trench-parallel flow induced by overriding plate structure. Earth and Planetary Science Letters, 401, pp.227-235.

Schmandt, B. and Humphreys, E., 2011. Seismically imaged relict slab from the $55 \mathrm{Ma}$ Siletzia accretion to the northwest United States. Geology, $39(2)$, p. $175-178$.

Shen, W. \& Ritzwoller, M.H., 2016. Crustal and uppermost mantle structure beneath the United States, J. geophys. Res., doi:10.1002/2016JB012887.

Sherrod D.R., Smith J.G., 2000. Geologic map of upper Eocene to Holocene volcanic and related rocks of the Cascade Range, Oregon: U.S. Geological Survey, Geologic Investigations Series - I-2569.

Sisson, T.W. and Bronto, S., 1998. Evidence for pressure-release melting beneath magmatic arcs from basalt at Galunggung, Indonesia. Nature, 391(6670), p. 883-886.

Sleep, N.H., 2005. Evolution of the continental lithosphere. Annu. Rev. Earth Planet. Sci., 33, pp.369-393.

Slingerland, R., Kump, L., 2011. Mathematical Modeling of Earth's Dynamical Systems: A Primer. Princeton University Press.

Stachnik, J.C., Abers, G.A. and Christensen, D.H., 2004. Seismic attenuation 
and mantle wedge temperatures in the Alaska subduction zone. Journal of Geophysical Research: Solid Earth, 109(B10), doi:10.1029/2004JB003018.

Stern, R.J., 2002. Subduction zones. Reviews of geophysics, 40(4).

Stevenson, D.J. and Turner, J.S., 1977. Angle of subduction. Nature, 270(5635), pp.334-336.

Syracuse, E.M. and Abers, G.A., 2006. Global compilation of variations in slab depth beneath arc volcanoes and implications. Geochemistry, Geophysics, Geosystems, 7(5), doi:10.1029/2005GC001045.

Syracuse, E.M., van Keken, P.E. and Abers, G.A., 2010. The global range of subduction zone thermal models. Physics of the Earth and Planetary Interiors, 183(1), p. 73-90.

Turcotte, D.L. and Schubert, G., 2014. Geodynamics. Cambridge University Press.

Till, C.B., Grove, T.L., Carlson, R.W., Donnelly-Nolan, J.M., Fouch, M.J., Wagner, L.S. and Hart, W.K., 2013. Depths and temperatures of $<10.5$ Ma mantle melting and the lithosphere-asthenosphere boundary below southern Oregon and northern California. Geochemistry, Geophysics, Geosystems, 14(4), p. 864-879, http://dx.doi.org/10.1002/ggge.20070.

Turner, S.J. and Langmuir, C.H., 2015. What processes control the chemical compositions of arc front stratovolcanoes?. Geochemistry, Geophysics, Geosystems, 16(6), p. 1865-1893.

Tsumura, N., Matsumoto, S., Horiuchi, S. and Hasegawa, A., 2000. Threedimensional attenuation structure beneath the northeastern Japan arc estimated from spectra of small earthquakes. Tectonophysics, 319(4), p. 241-260.

van Keken, P.E., 2003. The structure and dynamics of the mantle wedge. Earth and planetary science letters, 215(3), p. 323-338.

van Keken, P.E., Currie, C., King, S.D., Behn, M.D., Cagnioncle, A., He, J., Katz, R.F., Lin, S.C., Parmentier, E.M., Spiegelman, M. and Wang, K., 2008. A community benchmark for subduction zone modeling. Physics of the Earth and Planetary Interiors, 171(1), pp.187-197.

Wada, I., Rychert, C.A. and Wang, K., 2011. Sharp thermal transition in the forearc mantle wedge as a consequence of nonlinear mantle wedge flow. Geophysical Research Letters, 38(13).

Wada, I. and Wang, K., 2009. Common depth of slab-mantle decoupling: Reconciling diversity and uniformity of subduction zones. Geochemistry, 
Geophysics, Geosystems, 10(10), doi:10.1029/2009GC002570.

Wada, I., Wang, K.L., He, J.G., Hyndman, R.D., 2008. Weakening of the subduction interface and its effects on surface heatflow, slab dehydration, and mantle wedge serpentinization. J. Geophys. Res. 113, B04402, doi:10.1029/2007JB005190.

Wagner, L.S., Fouch, M.J., James, D.E. and Hanson-Hedgecock, S., 2012. Crust and upper mantle structure beneath the Pacific Northwest from joint inversions of ambient noise and earthquake data. Geochemistry, Geophysics, Geosystems, 13(12).

Wells R.E., Blakely R.J., Simpson R.W., Weaver C.S., Haugerud R., Wheeler K., 2000. Tectonic plate motions, crustal blocks, and shallow earthquakes in Cascadia: http://geomaps.wr.usgs.gov/pacnw/rescasp1.html (acessed Febuary 2016).

Wiens, D.A. and Smith, G.P., 2003. Seismological constraints on structure and flow patterns within the mantle wedge. Inside the Subduction Factory, p. 59-81.

Wilson, D.S., 1988. Tectonic history of the Juan de Fuca Ridge over the last 40 million years. Journal of Geophysical Research: Solid Earth, 93(B10), p. $11863-11876$. 